Journalof BANKING \&

FINANCE

\title{
Fundamental determinants of national equity market returns: A perspective on conditional asset pricing
}

\author{
Wayne E. Ferson ${ }^{\mathrm{a}, *}$, Campbell R. Harvey ${ }^{\mathrm{b}, 1}$ \\ ${ }^{a}$ Department of Finance and Business Economics, University of Washington, Box 353200, Seattle, \\ WA 98195-3200, USA \\ ${ }^{\mathrm{b}}$ Fuqua School of Business, Duke University, Durham, NC 27708-0120, USA
}

\begin{abstract}
This paper provides a global asset pricing perspective on the debate over the relation between predetermined attributes of common stocks, such as ratios of price-to-bookvalue, cash-flow, earnings, and other variables to the future returns. Some argue that such variables may be used to find securities that are systematically undervalued by the market, while others argue that the measures are proxies for exposure to underlying economic risk factors. It is not possible to distinguish between these views without explicitly modelling the relation between such attributes and risk factors. We present an empirical framework for attacking the problem at a global level, assuming integrated markets. Our perspective pulls together the traditional academic and practitioner viewpoints on lagged attributes. We present new evidence on the relative importance of risk and mispricing effects, using monthly data for 21 national equity markets. We find that the cross-sectional explanatory power of the lagged attributes is related to both risk and mispricing in the two-factor model, but the risk effects explain more of the variance than mispricing. (C) 1998 Elsevier Science B.V. All rights reserved.
\end{abstract}

JEL classification: G12; G14

\footnotetext{
${ }^{*}$ Corresponding author. Tel.: +1 206543 1843; fax: +1 2066859392 .

${ }^{1}$ Tel.: 919-660-7768; fax: 919-661-6246; e-mail: charvey@mail.duke.edu; web: http://www.duke.edu/ charvey.
} 
Keywords: Asset pricing; Factor models; Market efficiency; Asset allocation

\section{Introduction}

Empirical work on international asset pricing usually follows in the footsteps of "domestic" asset pricing studies. For example, early studies focussed on international applications of the Capital Asset Pricing Model (CAPM), originally developed in a domestic context by Sharpe (1964) and Lintner (1965). The model was internationalized by allowing investors to differ across countries, according to their preferred currency or consumption basket (e.g. Solnik, 1977; Stulz, 1981a, 1984; Adler and Dumas, 1983). Empirical work, following the early studies of the domestic CAPM, first focussed on the relation between average returns and the average, or unconditional betas.

Beginning in the early 1980s, asset pricing studies began to take seriously the dynamic behaviour of asset market returns, allowing for time-varying expected returns and measures of asset risk that are conditioned on instruments for the state of the economy. Once again, international work in most cases followed on the heels of domestic asset pricing studies. ${ }^{2}$

More recently, domestic asset pricing research has focussed on the ability to predict a cross-section of stock returns using lagged values of firm attributes such as market capitalization, ratios of price-to-book-value, cash-flow-to-price, earnings-to-price and other similar measures. Once again, international work has lagged behind. ${ }^{3}$ This paper exploits that fact to present new evidence from a global asset pricing perspective on this new strand of research. We argue that the recent availability of detailed data on attributes across countries presents exciting new opportunities, as well as challenges for global asset pricing models.

The domestic asset pricing literature remains in a state of controversy over why lagged firm-specific attributes should predict returns. There are several competing points of view. Some argue that such variables are fundamental val-

\footnotetext{
${ }^{2}$ See, for example, Hansen and Singleton (1983) followed by Wheatley (1988), Bollerslev et al. (1988) followed by Engel and Rodrigues (1989), Ferson (1990) followed by Brown and Otsuki (1990b); Harvey (1989, 1991a, b) and Ferson and Harvey (1991, 1993). Of course, there are exceptions to the general pattern, in which international studies develop first approaches used later in a domestic setting. These include Hansen and Hodrick (1983) followed by Gibbons and Ferson (1985) and Frankel (1982) followed by Ferson et al. (1987).

${ }^{3}$ See Chan et al. (1991) for an early study for Japan. Ferson and Harvey (1994b) provide an exploratory investigation of the relation between risk, return and a number of attributes at the country level. See also $\mathrm{Ng}$ et al. (1994) for a recent paper which explicitly models the relation between attributes and risk at the firm level.
} 
uation measures, which may be used to find securities that are systematically undervalued by the market (e.g. Graham and Dodd, 1934; Lakonishok et al., 1994; Haugen and Baker, 1996). Others argue that the measures are proxies for exposure to underlying economic risk factors that are rationally priced in the market (e.g. Fama and French, 1993, 1996). A third view is that the observed predictive relations are largely the result of various biases in the data (e.g. Black, 1993; Breen and Korajczyk, 1994; Shanken et al., 1995; Chan et al., 1995). Finally, Berk (1995) points out that because returns are related mechanically to price by the present value relation, ratios which have price in the denominator are likely to be related to expected returns by construction. As in most of the interesting debates in economics, there is likely to be a little truth in the arguments on all sides of this issue.

Our position in this debate emphasizes that it is not possible to distinguish between the mispricing view and the rational-risk-proxy view without being explicit about the economic risk factors. For example, Ferson (1996) argues that attribute-sorted portfolios of common stocks, as used in Fama and French $(1993,1996)$ and other recent studies as risk-factor proxies, will behave as if they are risk factors, even when the mispricing view is correct. This confounding of the effects of risk and mispricing is likely to be especially difficult in view of the insights of Berk (1995). Therefore, portfolios of common stocks sorted on the basis of an "anomaly" like the book-to-market effect, cannot discriminate between the two views. In this paper we therefore work with models in which the economic risk factors are explicitly specified, and we avoid the use of attribute-sorted individual stock returns.

Our empirical analysis is conducted using data at the country level. This has a number of advantages over previous work that has focussed on individual firms. Our data on the returns and attributes, which are obtained from Morgan Stanley, are constructed in "real" time. Therefore, we avoid look-ahead biases which may be present in studies using COMPUSTAT and similar sources of data on individual firms. Working at the aggregate, country-portfolio level there is no "survivorship" requirement that a firm has data at some future date in order to be included in the data base at the current date. This should mitigate survivorship biases.

Our study provides new evidence on the robustness of the empirical relations between stock returns and attributes similar to those that have been studied at the firm level within a country. We also provide evidence on the extent to which these attributes are consistent with models of asset pricing in integrated global equity markets.

This paper also forges a link between two large academic and practitioner literatures. In practice, quantitative investment strategists often regress future returns cross-sectionally on various predetermined attributes of firms and attempt to use these "factor models" both as risk models, and as an aid in discriminating high- from low-expected-return portfolio strategies. The factors 
may include accounting ratios, such as price-to-earnings or book value, measures of lagged returns, and volume, volatility, or measures of industry affiliation. Such an approach is sometimes called "composite modelling" by practitioners (e.g. Guerard and Takano, 1990). A few academic studies have recently followed a similar cross-sectional approach to modelling stock returns (e.g. Haugen and Baker, 1996; Brennan et al., 1996).

Traditionally, when academics think of factor models they have in mind time-series regressions of returns on economic factors or mimicking portfolios, as in the factor model regressions associated with the arbitrage pricing theory (APT) (Ross, 1976; Ross and Walsh, 1983). In this context the "factors" refer to economy-wide risk variables. This paper helps bridge the gap between the academic and practitioner perspectives, by integrating the cross-sectional analysis more closely with beta pricing theory. This merger presents benefits from each perspective.

From the asset pricing perspective we provide new evidence on the structure of expected returns across countries. We conduct tests of beta pricing models which incorporate predetermined attributes in a rigorous way, and we examine the hypothesis that they are proxies for risk exposures within the model. We find, for example, that the price-to-book-value ratio has cross-sectional explanatory power at the country level, mainly because of its information about global market risk exposures. Some attributes (e.g. "momentum") indicate abnormal returns relative to the model, while others reflect a mix of risk and "mispricing". Overall, risk effects explain more of the variance than mispricing effects.

From a practical perspective, we provide evidence on which factors in a composite model contribute to alpha, and which factors simply lead to systematic risk exposure. We also offer a framework for integrating stock selection models across countries. Existing models are difficult to combine across countries, because the value of an attribute like the price-to-earnings ratio has a different economic meaning in different countries. Countries differ dramatically in accounting conventions, dividend policies, and a host of other details which affect the economic interpretation of the numbers. By relating the attributes to risk exposures, we can adjust them to control for differences in the economic meaning across countries. We find that the cross-sectional explanatory power of some attributes, such as price-to-book is enhanced by making a risk-exposure adjustment.

Our approach could be expanded for use in other settings. For example, a similar approach could be used to control for industry differences, arising from accounting conventions and asset structures, within a country.

The paper is organized as follows. Section 2 describes the models and Section 3 describes the data. Section 4 presents our empirical results in three sections. First, we examine the relation of the fundamental attributes to global risk factors through the conditional betas. Second, we estimate time-series 
models which examine the extent to which the attributes are important beyond their roles as proxies for risk exposure, through the model's "alpha". Third, we present evidence on the cross-sectional determinants of the national equity market returns. Section 5 offers concluding remarks.

\section{Attributes and asset pricing models}

Asset pricing theories postulate that differences in expected returns are related to the covariances of securities with marginal utility. The marginal utility may depend on several economic risk factors, in which case several "betas" may be required to measure risk. Firm-specific attributes have traditionally served as alternatives to beta in tests of these asset pricing models. For example, the firm "size-effect" first drew attention as a challenge to the CAPM. The literature continued in this tradition with the ratios of stock market price to earnings and the book value of equity (e.g. Basu, 1977; Chan et al., 1991; Fama and French, 1992). The evidence of these studies suggests that such firm-specific attributes are important for explaining equity returns in the United States and Japan. Ferson and Harvey (1994b), find that similar variables are important at the country level.

A beta pricing model implies that predetermined attributes of firms or countries are useful cross-sectional predictors for future returns only to the extent that they are informative about the relevant betas of the assets. However, tests of asset pricing models have failed to fully develop the implications of this proposition. ${ }^{4}$ Firm or country attributes are valid alternative hypotheses to asset pricing models only to the extent that they are purged of their information about betas. In order to do this, it is necessary to model the relation of the betas to the attributes explicitly.

\subsection{The empirical models}

In order to explicitly model the relation of betas to the attributes we use an empirical framework that can be considered to have four components. The first is a generating process for unanticipated returns. In this paper, the generating process will be denoted as the factor model, because it links the returns to the underlying economic risk factors. For a given factor model, there is a natural beta pricing or APT model for the expected returns. The third component is a

\footnotetext{
${ }^{4}$ Some studies have regressed returns on both the attributes and separate estimates of the betas. But the attributes are likely to be correlated with the "true" betas, and the true betas are likely to be measured with error. This situation makes the regressions difficult to interpret. See, for example, $\operatorname{Kim}(1995)$.
} 
model for the conditional betas. Finally, we append a model for abnormal returns, or alphas. Consider the case of a single factor model, where the world market index excess return, $r_{\mathrm{m}, t+1}$, is the risk factor. The generating process or factor model is given by Eq. (1):

$$
\begin{aligned}
& r_{i, t+1}=E_{t}\left(r_{i, t+1}\right)+\beta_{i t}\left\{r_{\mathrm{m}, t+1}-E_{t}\left(r_{\mathrm{m}, t+1}\right)\right\}+\epsilon_{i, t+1}, \\
& E_{t}\left(\epsilon_{i, t+1}\right)=0, \\
& E_{t}\left(\epsilon_{i, t+1} r_{\mathrm{m}, t+1}\right)=0,
\end{aligned}
$$

where $r_{i, t+1}$ is the return for country $i$, measured in a common currency (which we take to be US dollars), net of the return to a one-month Treasury bill. The notation $E_{t}($.$) indicates the conditional expectation, given a common$ public information set at time $t$. The factor model expresses the unanticipated return of country $i$, which is $r_{i, t+1}-E_{t}\left(r_{i, t+1}\right)$, as a linear regression on the unanticipated part of the market factor. The error terms $\epsilon_{i, t+1}$ may be correlated across countries. The coefficient $\beta_{i t}$ is the conditional beta of the return of country $i$ on the market factor (this is content of the third line of Eq. (1)). We use the following model for the conditional expected returns and the betas:

$$
\begin{aligned}
& E_{t}\left(r_{i, t+1}\right)=\alpha_{i t}+\beta_{i t} E_{t}\left(r_{\mathrm{m}, t+1}\right), \\
& \beta_{i t}=b_{0 i}+b_{1 i}^{\prime} Z_{t}+b_{2 i}^{\prime} A_{i t}, \\
& \alpha_{i t}=\alpha_{0 i}+\alpha_{1 i}^{\prime} Z_{t}+\alpha_{2 i}^{\prime} A_{i t},
\end{aligned}
$$

where $A_{i t}$ is a vector of attributes for security $i$ that are known at time $t, Z_{t}$ is a vector of world market-wide information variables known at time $t$, and the parameters of the model are $\left\{b_{0 i}, b_{1 i}, b_{2 i}, \alpha_{0 i}, \alpha_{1 i}, \alpha_{2 i}\right\}$.

When $\alpha_{i t}=0$ (that is, the parameters $\alpha_{0 i}, \alpha_{1 i}, \alpha_{2 i}$ are zero), the first line of Eq. (2) corresponds to the predictions of a beta pricing or APT model using the world market as the risk factor. Assuming that alpha is zero is equivalent to assuming that the error term $\epsilon_{i, t+1}$ in Eq. (1) is not priced.

The second line of Eq. (2) is the model for the conditional betas. Following Rosenberg and Marathe (1979), the betas are modelled as linear functions of the predetermined attributes. We use notation that distinguishes the fundamental attributes of the country $i$ from the common, global information variables, denoted by $Z_{t}$. The coefficient $b_{2 i}$ describes the response of the conditional beta of country $i$ to the attribute $A_{i t}$.

We generalize Rosenberg and Marathe (1979) by allowing country-specific coefficients in the model for beta. Thus, the relation between an attribute, like the book-to-market ratio, and beta is allowed to differ across the countries. The relation may differ across countries because of differences in the accounting conventions used to compute earnings, depreciation and book values, as well 
as other factors. For example, high cross-holdings of corporate shares in Japan is widely regarded to have inflated price-to-earnings ratios in Japan relative to the United States (e.g. Kester and Luehrman, 1989; Ando and Auerbach, 1990).

Given evidence that the conditional covariances of national market returns move over time in association with lagged variables (e.g. King et al., 1994; Harvey (1991a, b)), and evidence of time-varying betas for international asset returns (e.g. Giovannini and Jorion, 1987, 1989; Mark, 1985; Ferson and Harvey, 1993, 1994b), the model allows for time-variation in the conditional betas. This time-variation in the model comes from time-variation in either the attributes or the world information variables, $Z_{t}$. In Eq. (2), the relation over time between attributes and betas for a given country is assumed to be stable, as $b_{2 i}$ is a fixed coefficient. However, we also examine models estimated on rolling windows, an approach that allows $b_{2 i}$ to vary over time.

We allow for deviations from the predictions of the asset pricing model through the abnormal return, or alpha. The third line of Eq. (2) states that the alpha is a linear function of the set of world economic information variables, denoted by the vector $Z_{t}$, and of the attribute $A_{i t}$. The coefficient $\alpha_{0 i}$ is the usual intercept term. The coefficient on the attribute, $\alpha_{2 i}$, should be zero if the explanatory power of the attribute is confined to its role as a proxy for risk exposure. This provides a natural test of the asset pricing model, where mispricing related to the attribute is the alternative hypothesis. Testing for $\alpha_{2 i}=0$ in system (2) asks whether an attribute can predict returns over and above its role as an indicator for beta risk.

The models for both the betas and the alphas, as given by Eq. (2), are likely to be imperfect. The second and third equations of (2) may have independent error terms, reflecting possible misspecification of the alphas and the betas. 5

\subsection{Interpreting the model}

To illustrate some implications of the model, consider the cross-sectional regression

$$
r_{i t+1}=\gamma_{0, t+1}+\gamma_{1, t+1}^{\prime} A_{i t}+e_{i t+1} ; \quad i=1, \ldots, N,
$$

\footnotetext{
${ }^{5}$ Of course, this does not fully address the issue of a misspecified risk model. If we leave out a priced risk factor in our model, and if the country attributes are correlated with the betas on the missing factor, it can appear in our model as if the attribute enters as mispricing. In that sense, our empirical work is biased against a risk-based explanation of the role of the country attributes in expected returns.
} 
where $\gamma_{0, t+1}$ is the intercept, $\gamma_{1, t+1}$ is the slope coefficient, and $A_{i t}$ is the fundamental attribute, say the price-to-book ratio, for country $i$ in month $t$. The dating convention indicates that the attribute is public information at time $t$. When there are multiple attributes, so that $A_{i t}$ and $\gamma_{1, t+1}$ are vectors, regression (3) is the backbone of a typical composite model for stock selection. Similar regressions are used in asset pricing studies (e.g. Fama and MacBeth, 1973; Ferson and Harvey, 1991; Fama and French, 1992).

The coefficient $\gamma_{1, t+1}$ in Eq. (3) is the return of an arbitrage portfolio. This is a zero net investment, maximum correlation portfolio for the attribute. The portfolio weights depend on the cross-section of the attributes observed at time $t$. The expected values of the coefficients represent expected return premia associated with the attribute. (Such a portfolio may be used in practice in a "tilt" investment strategy.)

The asset pricing hypothesis is that alpha is zero in Eq. (2). In this case, $E_{t}\left(r_{i, t+1}\right)=\beta_{i t} E_{t}\left(r_{\mathrm{m}, t+1}\right)$, and the only variables differing across country $i$ in the expressions for the expected returns are the conditional betas, $\beta_{i t}$. Rational expectations implies that the differences between the actual returns at time $t+1$ and the conditional expected returns $E_{t}\left(r_{i, t+1}\right)$, using information at time $t$, should not be predictable using information at time $t$. Therefore, if the cross-sectional regression (3) has explanatory power, the asset pricing model implies that the attributes proxy for the underlying risk exposures, as measured by the betas.

If the relation between a fundamental attribute and a risk exposure is not the same across countries (that is, if $b_{2 i}$ is not the same for all $i$ in Eq. (2)) then the cross-sectional regression of Eq. (3) is misspecified. However, a regression of $r_{i, t+1}$ on $\left(b_{0 i}+b_{1 i} Z_{t}+b_{2 i} A_{i t}\right)$ may be well-specified, and its cross-sectional coefficient should be the market excess return $r_{\mathrm{m}, t+1}$, if $\alpha_{i t}$ is zero. We reject the hypothesis that the coefficients are equal across countries, and therefore explore to what extent a risk-exposure adjustment can improve the explanatory power of the attributes in cross-sectional regressions.

If an attribute enters through mispricing, and if expected returns bear a different relation to the attribute in different countries (i.e. if $\alpha_{2 i}$ differs across countries), this is another source of potential misspecification in the cross-sectional regression (3). We therefore explore whether replacing the attribute $A_{i t}$ with the term $\left(\alpha_{0 i}+\alpha_{1 i}^{\prime} Z_{t}+\alpha_{2 i} A_{i t}\right)$ can improve the explanatory power.

\subsection{Implementing the model}

Combining Eqs. (1) and (2), we derive the following econometric model:

$$
r_{i t+1}=\left(\alpha_{0 i}+\alpha_{1 i}^{\prime} Z_{t}+\alpha_{2 i} A_{i t}\right)+\left(b_{0 i}+b_{1 i} Z_{t}+b_{2 i} A_{i t}\right) r_{\mathrm{m}, t+1}+u_{i, t+1} .
$$

When Eq. (4) is estimated as a time-series regression, OLS estimation imposes the same moment conditions as does the Generalized Method of Moments 
(GMM) estimator [Hansen (1982)] of a conditional beta. ${ }^{6}$ In other words, the parameters are estimated so that the term $\left(b_{0 i}+b_{1 i} Z_{t}+b_{2 i} A_{i t}\right)$ is the conditional beta of country $i$ on the market factor.

Under the null hypothesis, regression model (4) should be robust to the form of the expected risk premiums, $E_{t}\left(r_{\mathrm{m}, t+1}\right)$. The expected risk premiums may depend on the world information variables, as in Ferson and Harvey (1993), or they may depend on the world variables and the country attributes, or possibly on other information. The risk premiums could even be constant over time, and regression (4) should still be well specified. ${ }^{7}$ This robustness to the functional form of the expected risk premiums is attractive in view of the possibility that the relation between the expected factor risk premiums and the predetermined variables could be subject to a data mining bias.

All of the preceding analysis extends naturally to handle models with more than a single market factor. We examine two-factor models, using a measure of exchange risks as a second factor. In the two-factor model, we include the additional terms $\left(c_{0 i}+c_{1 i} Z_{t}+c_{2 i} A_{i t}\right) r_{x, t+1}$ in Eq. (4), where $r_{x, t+1}$ is the exchange risk variable described below, and $\left(c_{0 i}+c_{1 i} Z_{t}+c_{2 i} A_{i t}\right)$ is the model for the exchange risk beta. Multiple attributes are handled simply by letting $A_{i t}, b_{2 i}$ and $c_{2 i}$ become vectors.

\footnotetext{
${ }^{6}$ Consider a linear conditional beta $\beta_{t-1}=b+B^{\prime} z_{t-1}$ in a linear regression model $y_{t}=x_{t}^{\prime} \beta_{t-1}+\epsilon_{t}$. The moment conditions:$$
u_{t}=x_{t} y_{t}-\left(x_{t} x_{t}^{\prime}\right)\left(b+B z_{t-1}\right), \quad E\left(u_{t} \mid z_{t-1}\right)=0
$$

would be the basis of the GMM estimation. Typically, the implementation of the GMM would use the implication: $E\left(u_{t} \otimes z_{t-1}\right)=0$. Consider the OLS regression estimator of the linear model which results from substituting the beta equation into the regression and note that the error terms are related as $\epsilon_{t} x_{t}=u_{t}$. It is easy to verify that the two sets of moment conditions are the same.

${ }^{7}$ To see this, write $r_{m, t+1}=E_{t}\left(r_{m, t+1}\right)+\epsilon_{m, t+1}$ and note that the error term in Eq. (4) may be written, under the null hypothesis, as:

$u_{i t+1}=\left\{r_{i t+1}-E_{t}\left(r_{i, t+1}\right)\right\}-\beta_{i t}^{\prime} \epsilon_{t+1}$,

where $\beta_{i t}$ is the vector of conditional betas for country $i$ and $\epsilon_{t+1}$ is the vector of unexpected factor excess returns. Since the $\beta_{i t}$ are, under the null hypothesis, the conditional betas, $u_{i t+1}$ is the error from projecting the unanticipated country return $\left\{r_{i t+1}-E_{t}\left(r_{i t+1}\right)\right\}$ on the unanticipated factor excess returns, where $\beta_{i t}^{\prime} \epsilon_{t+1}$ is the projection. The error term $u_{i, t+1}$ should be orthogonal to both the public information set and the ex post factor return, $r_{m, t+1}$, and therefore to the right-hand side variables in the regression (4).
} 


\section{The data}

\subsection{National equity market returns}

Total returns for 21 countries are based on indexes from Morgan Stanley Capital International (MSCI). The returns are calculated with gross dividend reinvestment. They represent value-weighted portfolios of the larger firms traded on the national equity markets, and are designed to cover a minimum of $60 \%$ of the market capitalization. Returns are available from January 1970 except for Finland, Ireland and New Zealand (which begin in February 1988). A value-weighted world market portfolio is constructed as the aggregate of the 21 countries.

\subsection{Country attributes}

We examine three different groups of country attributes. The first is the relative valuation ratios. The second is lagged return and volatility, which we denote as "financial" variables ("fin" in the tables). The third group measures country macroeconomic performance, and we denote these as "mac" in the tables. The data series are available from different starting dates, the earliest of which is January of 1970 . We conduct most of our analysis using January 1975 through May 1993, or the shorter period for which all of the series are available for a given country. Here we motivate and briefly describe the variables. Appendix A contains more detailed descriptions.

\subsubsection{Valuation ratios}

Measures of value have long been used by equity analysts in their attempts to discriminate high- from low-expected return stocks (e.g. Graham and Dodd, 1934). A number of investment services characterize the "styles" of equity managers as "value" or "growth", largely on the basis of similar valuation ratios for the stocks they buy (e.g. Christopherson and Tritton, 1995; Morningstar, 1995). Quantitative stock selection models place a great deal of weight on valuation ratios for individual stocks in the United States and in other national markets (e.g. Rosenberg et al., 1985; Guerard and Takano, 1990; Wadhwani and Shah, 1993). With the recent work of Fama and French $(1992,1993,1996)$ and others, academics have become increasingly interested in valuation ratios. No previous study, however, has used such ratios at the country level to model the cross-section of conditional expected returns as we do in this paper. At the country level, Stulz and Wasserfallen (1995) suggest that differences in stock market price levels, other things held fixed, may proxy for their relative investability. If expected returns differ across countries with investability, we might also expect 
differences in valuation ratios to be related to differences in expected returns for this reason. ${ }^{8}$

We use four valuation ratios, obtained from MSCI. These are (1) Earningsto-price, (2) Price-to-cash flow, (3) Price-to-book-value and (4) Dividend yield. Earnings-to-price was one of the first valuation ratios to attract attention as an alternative to the CAPM for individual stocks (Basu, 1977). Our ratio is the value-weighted average of the individual ratios, averaged across the firms in the MSCI universe. To avoid the extreme outliers caused by near zero earnings, we use the ratio of earnings-to-price, rather than the inverse. Chan et al. (1991) found that a ratio of price-to-cash flow had a stronger relation to individual stock returns in Japan than a ratio of price-to-earnings. Our price-to-cash ratio defines cash as accounting earnings plus depreciation. Like the price-to-bookvalue ratio, this is a value-weighted average across the firms. Finally, we examine dividend yields, which are the lagged, 12 month moving sum of dividends divided by the current MSCI index level for each country.

Table 1 presents summary statistics of the four valuation ratios. To conserve space, we report statistics for an equal-weighted average of the variables, taken across the countries. The aggregate ratios are highly persistent through time, as indicated by their autocorrelations, similar to the lagged instruments used to model time-varying expected returns in a number of previous studies. Summary statistics and time-series plots of the valuation ratios for each country are reported in Ferson and Harvey (1994b). The valuation ratios typically show no strong trends over the sample period. A number of the series show episodes of relatively high and low volatility, suggestive of conditional heteroskedasticity. The price-to-earnings ratios are the most volatile of the valuation ratios and are occasionally negative, due in large part to low and negative earnings during the world recession in 1992.

\subsubsection{Lagged volatility and momentum}

Cross-sectional stock selection models used by practitioners typically include a measure of specific-return volatility and often include a measure of momentum (e.g. BARRA). Recent academic studies have also concentrated on understanding the risks and returns of momentum-based trading strategies (e.g. Jegadeesh and Titman, 1993; Conrad and Kaul, 1996).

We measure momentum for each country as the arithmetic average of the previous six monthly returns. ${ }^{9}$ Jegadeesh and Titman (1993) find that sorting

\footnotetext{
${ }^{8}$ To the extent that such effects are concentrated in smaller shares, we may understate their importance by using the MSCI indexes, which are heavily weighted towards the larger and more liquid issues.

${ }^{9}$ To avoid losing too much data, the first few observations in the time series of momentum use fewer lagged returns; e.g. the first observation is based on the past month, the second uses two months, and so on.
} 


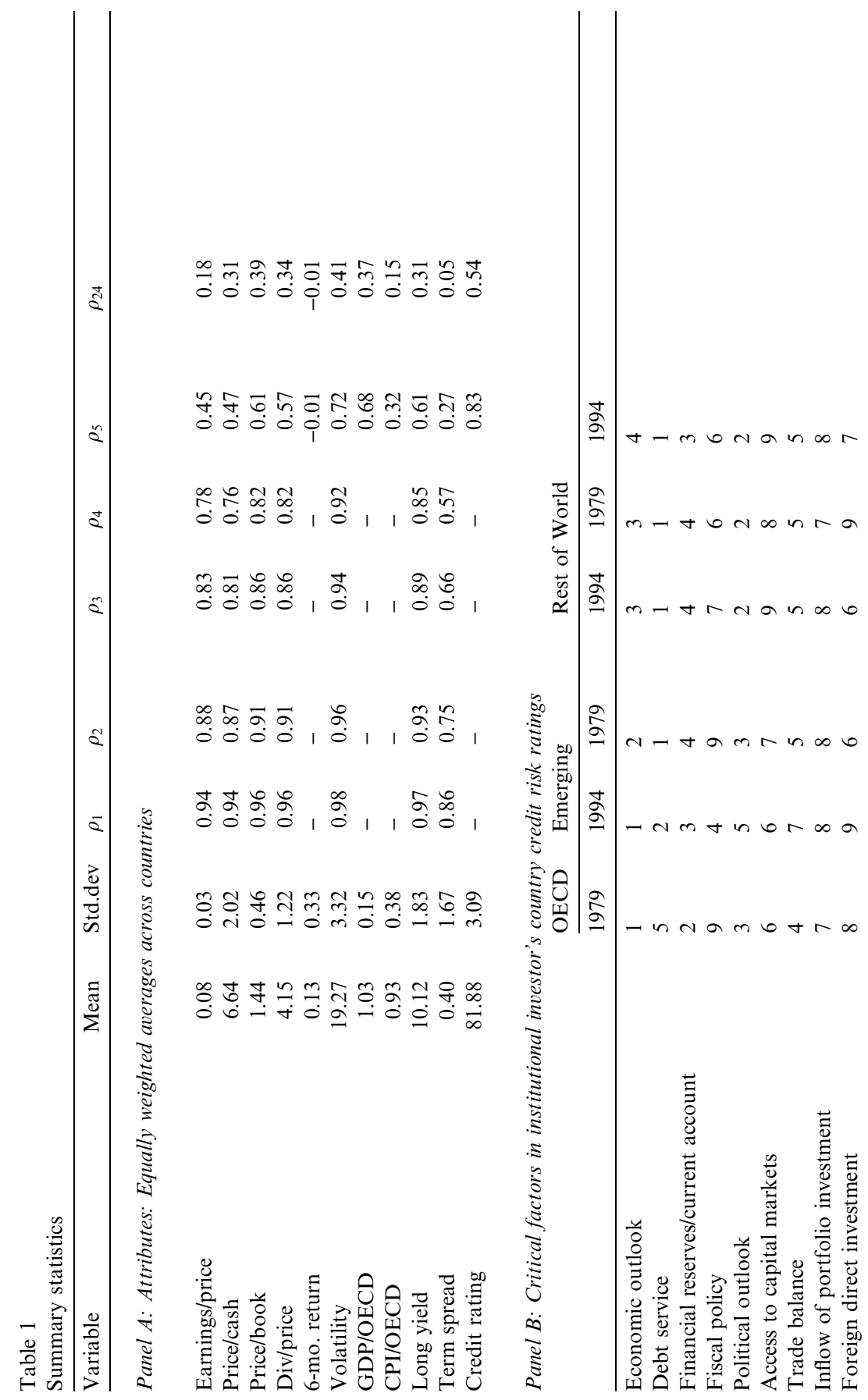




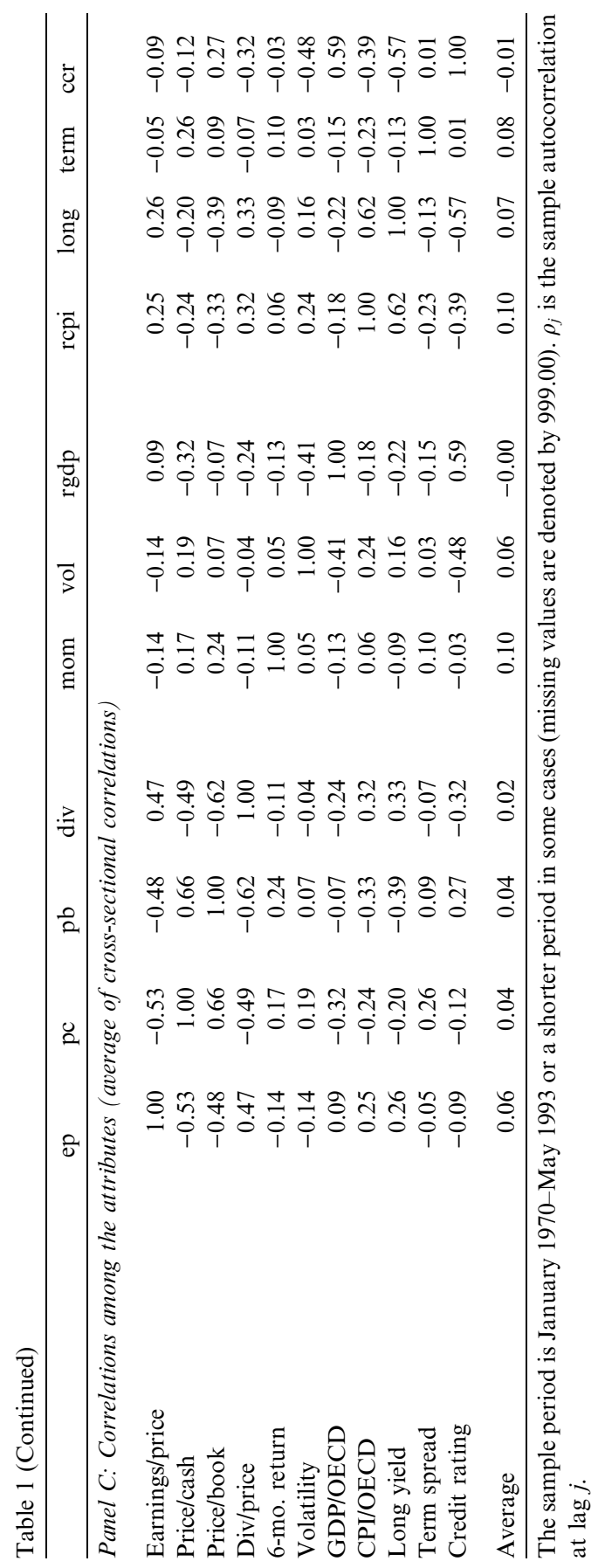


US common stocks on the basis of past returns, then buying the high-return stocks and shorting the low-return stocks produced large profits. Lagged returns over a 3-9 month period produced the most dramatic results. Conrad and Kaul (1996) show that most of this profit is attributable to the cross-sectional differences in the average returns of the stocks, as opposed to the autocorrelation of the stock returns. Our study provides evidence on the usefulness of a momentum attribute at the country level.

We measure lagged specific-return volatility by running a simple regression of a country return on the world index, using the past 60 months. The volatility is the standard deviation of the residual from this regression. Table 1 presents summary statistics for the momentum and volatility attributes, using an equally weighted average across the countries.

\subsubsection{Macroeconomic attributes}

At the country level, it makes sense that the attributes should include measures of relative economic performance, which is likely to be related to country exposure to global economy risks. We study four measures of country economic performance, designed to capture relative output, inflation and expected economic growth. These variables have the additional appeal that they are all "exogenous" in the sense that they come from outside the stock markets. Finally, we include a measure of country credit risk.

The first macroeconomic attribute is the ratio of lagged, quarterly gross domestic product (GDP) per capita, to lagged quarterly GDP per capita for the OECD countries, both measured in US dollars. GDP per capita is studied by Harris and Opler (1990), who find that stock market returns reflect forecasts of future output. Our second measure is relative inflation, measured monthly as the ratio of country inflation (annual percentage changes in the local CPI), to OECD annual inflation. Country inflation and inflation volatility, in relation to stock returns, are studied by Mandelker and Tandon (1985). A long term interest rate and a term spread are the final economic performance measures. Harvey $(1988,1991$ a) has shown that the slope of the term structure contains forecasts of future economic growth rates in a number of countries. Bond yields and spreads for individual countries are also used in predictive models by Ferson and Harvey (1993), Solnik (1993) and Wadhwani and Shah (1993). ${ }^{10}$

\subsubsection{Country credit ratings}

Institutional Investor credit ratings are based on a survey of leading international bankers who are asked to rate each country on a scale from zero to

\footnotetext{
${ }^{10}$ We use the long rate and the spread because their correlation is much lower than the correlation of the short rate and the spread or the short rate and the long rate. While the long rates are highly persistent, the sample autocorrelations damp out at longer lags.
} 
100 (where 100 represents maximum creditworthiness). Institutional Investor averages these ratings, providing greater weights to respondents with greater worldwide exposure and more sophisticated country analysis systems. Whenever a survey or expert panel is used to subjectively rate creditworthiness, it is hard to exactly define the parameters taken into account. At any given point in time an expert's recommendation will be based upon factors the expert feels are relevant. In order to identify the factors that its survey participants have taken into consideration in the past, Institutional Investor asks them to rank the factors that they take into account in preparing country ratings. The results of this survey are listed in panel B of Table 1. Note that the bankers rank factors differently for different groups of countries and that rankings have changed over time within country groups. The ranking of factors affecting the OECD country ratings appears to have been the most turbulent.

Panel A of Table 1 presents summary statistics for the macroeconomic attributes, reporting an equally weighted average across the countries. ${ }^{11}$ In Panel C we report a correlation matrix for the attributes. The correlations provide information about the cross-sectional relation, relevant for assessing collinearity in a cross-sectional model. For each month in the sample, a correlation between every pair of the attributes is computed, where the unit of observation is the country. The time-series average of the correlations is reported. The largest average correlation is between the price-to-book and price-to-cash ratios, and is 0.66 . Most are much smaller. This suggests that collinearity should not be a serious issue.

\subsection{Global risk factors}

Stulz (1981b, 1984) and Adler and Dumas (1983) provide conditions under which a single-beta CAPM based on a world market portfolio holds globally, which motivates the use of a world equity market risk factor. Empirical studies have used a similar risk factor with some success in a conditional asset pricing context (e.g., Giovannini and Jorion, 1989; Harvey, 1991a, b). We use the MSCI world excess return, which is the US dollar world market return less the US Treasury bill return.

Solnik (1974a, b) showed that exchange risks should be "priced" in a world otherwise similar to that of the static CAPM, when purchasing power parity

\footnotetext{
${ }^{11}$ In a pilot study (Ferson and Harvey, 1994b), we also measured the industry structure of a country using the coefficients from regressing the country returns on Morgan Stanley's international industry indices. Investment services, such as BARRA, use related industry structure measures in their models for individual stocks. We found that the measures of industry structure were not very informative about future relative returns across the countries.
} 
fails. Adler and Dumas (1983) present a model in which the world market portfolio and exchange risks are the relevant risk factors. The exchange risks can be broken down into a separate factor for each currency, as in Dumas and Solnik (1995), or can be approximated by a single variable, as in Ferson and Harvey (1993, 1994a). We use the G10 FX return, which is the US dollar return to holding a portfolio of the currencies of the G10 countries (plus Switzerland) in excess of the 30-day Eurodollar deposit rate. The currency return is the percentage change in the spot exchange rate plus the local currency, 30-day Eurodeposit rate. The currency returns are trade weighted to form a portfolio return (see Harvey, 1993b for details of the construction). This measure is similar to the one used by Ferson and Harvey (1993, 1994a), but it is measured directly as an excess return. This avoids the need to construct a mimicking portfolio for the factor in an asset pricing model.

If we are to provide valid inferences concerning the debate about whether firm attributes proxy for risk or mispricing, then the selection of the risk factors is critical. On the one hand, if we leave out relevant risk factors, we are likely to err on the side of mispricing. On the other hand, since it is possible to find a set of "factors" that appear to explain any specific mispricing, too many factors allow us to err on the side of priced risk. To minimize these errors we draw our factors from previous international asset pricing studies that did not use the predetermined country attribute data in selecting factors.

Previous studies have used a number of economic factors to represent risk, in addition to the market index and exchange risks. Such factors can be motivated by international versions of the Ross (1976) Arbitrage Pricing Model (e.g. Ross and Walsh, 1983) or the Merton (1973) intertemporal asset pricing model. A list of the most popular factors includes industrial production, unexpected inflation, changes in expected inflation, real interest rates, term structure risk and the price of crude oil (see, e.g. Hamao, 1988; Bodurtha et al., 1989; Brown and Otsuki, 1990a, b; Harris and Opler, 1990). Ferson and Harvey (1993, 1994a) examined all of these variables, measured as global aggregates, as potential risk factors for global asset pricing models. Based on a cross-section of average returns for developed countries, Ferson and Harvey (1994a) found that only the world stock market index and exchange risk factor betas had statistically significant unconditional risk premiums. Based on conditional returns, Ferson and Harvey (1993) found that most of the predictability in the returns over time is related to the world index. However, they did find evidence that additional risk factors can reduce the pricing errors of the one- or two-factor models.

We limit our analysis in this paper to the world market and exchange risk factors, which previous studies identify as the most important ones. Limiting the focus to two factors makes it likely that we err in the direction of attributing the affects of the country attributes to mispricing. However, it allows us to illustrate our arguments in a relatively simple setting. We hope that our exam- 
ples motivate future research relating country attributes explicitly to a richer set of economic risk factors.

\subsection{World information variables}

We include a number of predetermined worldwide information variables, similar to those which previous studies found can predict country returns over time, as the common set of conditioning information. The idea is that the expectations in the model should be conditioned on the current state of the global economy, as captured by such variables. The conditioning variables are the lagged values of the MSCI world market return, the G10 FX return, a world dividend yield, a short-term Eurodollar deposit rate and a term structure of interest rates measure taken from the Eurodollar market. The term spread is the difference between a 90-day Eurodollar deposit rate and the 30day Eurodollar deposit rate. The short term interest rate is the 30-day Eurodollar deposit yield which is observed on the last day of the month.

As the predetermined variables follow previous studies using similar variables, there is a natural concern that their predictive ability arises spuriously from data mining. However Solnik (1993) finds, using step ahead forecasts, that the predictability is economically significant. Ferson and Harvey (1993) find that a large fraction of the predictability, using similar variables, is related to premiums for economic factor risks. Even so, the possibility of data mining remains an important caveat. Most of the evidence of predictability mined from previous studies is based on regressing returns over time on these variables. Eq. (4) is robust to the specification of the expected factor premiums, as we argued above, which should reduce the effects of this source of bias.

\section{Empirical evidence}

\subsection{Are the attributes related to risk?}

Table 2 reports the results of estimating models for the conditional betas of the countries. Panel A uses a one-factor risk model, where the Morgan-Stanley world index is the risk factor. The remaining panels use a two-factor model, including the exchange risk variable as the second factor. We estimate the empirical model for beta given in the second line of Eq. (2) for each country, and test a number of hypotheses about which of the variables may be excluded from the model. We conduct the estimation using the GMM of Hansen (1982), and the following system of moment conditions:

$$
\begin{aligned}
& u_{\mathrm{w}, t+1}=r_{\mathrm{w}, t+1}-\delta_{\mathrm{w}}^{\prime} Z_{t}, \\
& u_{i, t+1}=\left(u_{\mathrm{w}, t+1} u_{\mathrm{w}, t+1^{\prime}}\right)\left[\left(Z_{t}, A_{i t}\right) B_{i}\right]^{\prime}-u_{\mathrm{w}, t+1} r_{i, t+1} .
\end{aligned}
$$


Table 2

Estimates of conditional betas

\begin{tabular}{|c|c|c|c|c|c|}
\hline \multirow[t]{2}{*}{ Country } & \multicolumn{5}{|c|}{$\begin{array}{l}\text { Attributes excluded from the model of conditional beta (right-tail } \\
p \text {-values of heteroskedasticity-consistent Wald tests are reported) }\end{array}$} \\
\hline & $\mathrm{x}$-inst & $\mathrm{x}$-val & $x$-fin & $\mathrm{x}-\mathrm{mac}$ & $\mathrm{x}$-all \\
\hline \multicolumn{6}{|c|}{ Panel A: One-factor models: world market beta } \\
\hline Australia & 0.150 & 0.003 & 0.308 & 0.522 & 0.000 \\
\hline Austria & 0.335 & 0.237 & 0.010 & 0.329 & 0.026 \\
\hline Belgium & 0.148 & 0.148 & 0.925 & 0.165 & 0.098 \\
\hline Canada & 0.131 & 0.084 & 0.454 & 0.132 & 0.000 \\
\hline Denmark & 0.821 & 0.325 & 0.070 & 0.214 & 0.173 \\
\hline Finland & 0.864 & 0.998 & 0.826 & 0.445 & 0.379 \\
\hline France & 0.106 & 0.395 & 0.289 & 0.180 & 0.005 \\
\hline Germany & 0.089 & 0.015 & 0.078 & 0.122 & 0.000 \\
\hline Hong Kong & 0.178 & 0.744 & 0.845 & 0.990 & 0.074 \\
\hline Ireland & 0.758 & 0.009 & 0.723 & 0.775 & 0.000 \\
\hline Italy & 0.021 & 0.359 & 0.654 & 0.008 & 0.000 \\
\hline Japan & 0.699 & 0.457 & 0.609 & 0.953 & 0.342 \\
\hline Netherlands & 0.014 & 0.028 & 0.121 & 0.158 & 0.000 \\
\hline New Zealand & 0.288 & 0.302 & 0.355 & 0.598 & 0.626 \\
\hline Norway & 0.684 & 0.272 & 0.379 & 0.412 & 0.001 \\
\hline Singapore/Malaysia & 0.915 & 0.040 & 0.847 & 0.242 & 0.007 \\
\hline Spain & 0.243 & 0.517 & 0.071 & 0.017 & 0.000 \\
\hline Sweden & 0.091 & 0.076 & 0.279 & 0.007 & 0.011 \\
\hline Switzerland & 0.245 & 0.968 & 0.779 & 0.204 & 0.312 \\
\hline UK & 0.812 & 0.790 & 0.037 & 0.895 & 0.114 \\
\hline US & 0.351 & 0.739 & 0.539 & 0.007 & 0.046 \\
\hline Multivariate & 0.298 & 0.053 & 0.205 & 0.149 & 0.000 \\
\hline \multicolumn{6}{|c|}{ Panel B: Two-factor models: world market betas } \\
\hline Australia & 0.068 & 0.241 & 0.952 & 0.762 & 0.000 \\
\hline Austria & 0.971 & 0.138 & 0.004 & 0.851 & 0.027 \\
\hline Belgium & 0.518 & 0.305 & 0.292 & 0.041 & 0.014 \\
\hline Canada & 0.494 & 0.445 & 0.417 & 0.164 & 0.000 \\
\hline Denmark & 0.502 & 0.092 & 0.141 & 0.482 & 0.083 \\
\hline France & 0.715 & 0.171 & 0.454 & 0.087 & 0.022 \\
\hline Germany & 0.056 & 0.045 & 0.197 & 0.252 & 0.002 \\
\hline Hong Kong & 0.370 & 0.386 & 0.661 & 0.842 & 0.242 \\
\hline Italy & 0.671 & 0.803 & 0.238 & 0.255 & 0.008 \\
\hline Japan & 0.602 & 0.624 & 0.953 & 0.900 & 0.162 \\
\hline Netherlands & 0.007 & 0.035 & 0.039 & 0.193 & 0.000 \\
\hline Norway & 0.172 & 0.151 & 0.344 & 0.055 & 0.000 \\
\hline Singapore/Malaysia & 0.848 & 0.046 & 0.796 & 0.159 & 0.002 \\
\hline Spain & 0.404 & 0.889 & 0.172 & 0.109 & 0.000 \\
\hline Sweden & 0.175 & 0.371 & 0.248 & 0.016 & 0.015 \\
\hline Switzerland & 0.132 & 0.783 & 0.588 & 0.066 & 0.014 \\
\hline UK & 0.454 & 0.865 & 0.115 & 0.667 & 0.076 \\
\hline US & 0.631 & 0.296 & 0.240 & 0.132 & 0.007 \\
\hline Multivariate & 0.121 & 0.639 & 0.065 & 0.295 & 0.000 \\
\hline
\end{tabular}


Table 2 (Continued)

\begin{tabular}{|c|c|c|c|c|c|}
\hline \multirow[t]{2}{*}{ Country } & \multicolumn{5}{|c|}{$\begin{array}{l}\text { Attributes excluded from the model of conditional beta (right-tail } \\
p \text {-values of heteroskedasticity-consistent Wald tests are reported) }\end{array}$} \\
\hline & $x$-inst & $\mathrm{x}$-val & $x$-fin & $\mathrm{x}$-mac & $\mathrm{x}$-all \\
\hline \multicolumn{6}{|c|}{ Panel C: Two-factor models: exchange rate betas } \\
\hline Australia & 0.745 & 0.823 & 0.017 & 0.184 & 0.039 \\
\hline Austria & 0.935 & 0.119 & 0.373 & 0.148 & 0.592 \\
\hline Belgium & 0.421 & 0.565 & 0.214 & 0.022 & 0.002 \\
\hline Canada & 0.090 & 0.713 & 0.052 & 0.210 & 0.041 \\
\hline Denmark & 0.054 & 0.295 & 0.186 & 0.043 & 0.046 \\
\hline France & 0.221 & 0.441 & 0.236 & 0.316 & 0.207 \\
\hline Germany & 0.394 & 0.784 & 0.982 & 0.906 & 0.116 \\
\hline Hong Kong & 0.500 & 0.013 & 0.166 & 0.049 & 0.060 \\
\hline Italy & 0.785 & 0.065 & 0.151 & 0.226 & 0.221 \\
\hline Japan & 0.471 & 0.875 & 0.649 & 0.646 & 0.055 \\
\hline Netherlands & 0.553 & 0.553 & 0.068 & 0.244 & 0.181 \\
\hline Norway & 0.298 & 0.055 & 0.397 & 0.093 & 0.001 \\
\hline Singapore/Malaysia & 0.786 & 0.760 & 0.154 & 0.068 & 0.001 \\
\hline Spain & 0.976 & 0.705 & 0.475 & 0.890 & 0.509 \\
\hline Sweden & 0.886 & 0.717 & 0.582 & 0.054 & 0.069 \\
\hline Switzerland & 0.494 & 0.153 & 0.175 & 0.163 & 0.035 \\
\hline UK & 0.190 & 0.035 & 0.630 & 0.394 & 0.036 \\
\hline US & 0.643 & 0.083 & 0.286 & 0.433 & 0.147 \\
\hline Multivariate & 0.965 & 0.237 & 0.306 & 0.402 & 0.013 \\
\hline
\end{tabular}

In system (5) $r_{\mathrm{w}, t+1}$ is the excess return of the global risk factors. In the one-factor model, $r_{\mathrm{w}}$ is the world market index. In the two-factor model, $r_{\mathrm{w}}$ is a $2 \times 1$ vector containing the market index and the exchange risk factor. The coefficient $\delta_{\mathrm{w}}$ is the regression coefficient vector of the risk factors on the $L_{\mathrm{w}}$-vector of the world information variables, which includes a constant. The error term $u_{\mathrm{w}, t+1}$ in the first line therefore represents the unanticipated part of the global risk factors. System (5) assumes that the expected risk premium for the world market and exchange risk factors depend only on the global information variables $Z_{\mathrm{t}}$. While this assumption is made to keep the size of the system of equations manageably small, it can also be motivated by an assumption of market integration (see Ferson and Harvey, 1993).

The second line of Eq. (5) identifies $\left[\left(Z_{t}, A_{i t}\right) B_{i}\right]$ as the $1 \times K$ vector of conditional betas for country $i$, assuming there are $K(=1$ or 2$)$ risk factors in the model. This line is essentially the normal equation which defines a conditional beta. If $A_{i t}$ is an $L_{i}$-vector of attributes for country $i$, then $B_{i}$ is a matrix of $\left(L_{\mathrm{w}}+L_{i}\right) \times K$ parameters.

The formulation of the conditional beta model in system (5) has the advantage that it does not take a stand on the form of the asset pricing model for the conditional expected returns for country $i$. This allows us to model the conditional betas without concern about getting the asset pricing model correct. 
Table 2 reports the results of a number of hypothesis tests based on the model of system (5). We are interested in finding the important predictors of the conditional betas. The attributes are grouped for testing purposes as follows: $v a l=\{\mathrm{ep}, \mathrm{pc}, \mathrm{pb}, \operatorname{div}\}, \mathrm{fin}=\{\mathrm{vol}, \operatorname{mom}\}, \operatorname{mac}=\{\operatorname{rgdp}$, rcpi, long, term, $\mathrm{ccr}\}$. The individual attributes are: $\mathrm{ep}=$ earnings-to-price ratio, $\mathrm{pc}=$ price-tocash flow ratio, $\mathrm{pb}=$ price-to-book-value ratio, $\mathrm{div}=$ dividend yield, mom $=$ six-month lagged average return, a measure of momentum, $\mathrm{vol}=$ lagged volatility, $\mathrm{rgdp}=$ real gross domestic product measured relative to $\mathrm{OECD}$, rcpi=consumer price index inflation rate, relative to OECD, long $=$ long term bond yield, term $=$ term structure slope, $c c r=$ country credit risk measure. The lagged, world market information variables $Z_{t}$ are the lagged world market index return, a world dividend yield, a short term Eurodollar deposit rate and a term spread from the Eurodollar market.

Table 2 reports the right-tail $p$-values of joint heteroskedasticity-consistent Wald tests for groups of the attributes. We examine separate exclusion restrictions for the valuation ratios (denoted by $x$-val), the financial attributes (x-fin), the macroeconomic attributes (x-mac), and the world information variables ( $\mathrm{x}-$ inst). Finally, we present tests of the exclusion hypotheses for all of the attributes except the intercept (x-all), which is the hypothesis that the conditional betas are constant over time. The bottom rows of each panel report joint tests for exclusion across the countries based on the Bonferroni inequality. ${ }^{12}$

The tests in Table 2 produce some interesting results for the modelling of country risk exposures. First, the overall exclusion tests provide strong evidence of time-varying betas, for the majority of the countries and jointly across the countries. Second, the lagged worldwide instruments are the weakest variables in the models for beta. They are never jointly significant across countries and rarely significant for the individual countries. It appears that the information content about time-varying conditional betas contained in the world instruments is effectively subsumed by the other, country-specific attributes.

Ferson and Harvey (1993) argued that it makes a priori sense to model conditional betas as a function of only country-specific variables, if the objective is to explain expected returns over time. Their logic was that the expected returns, under the model, depend on the products of betas and risk premiums. Average risk premiums are smaller numbers than betas, and it follows that assuming the betas depend only on country-specific variables, the model leaves out what

\footnotetext{
${ }^{12}$ Consider the event that any of $N$ statistics for a test of size $p$ rejects the hypothesis. Given dependent events, the joint probability is less than or equal to the sum of the individual probabilities. The Bonferroni $p$-value places an upper bound on the $p$-value of a joint test across the equations. It is computed as the smallest of the $N p$-values for the individual tests, multiplied by $N$, which is the number of countries.
} 
should be one of the smaller terms in the equation which describes time-variation in expected returns.

The tests in Table 2 are interesting in that they do not evaluate the importance of the world information variables in relation to their influence on the country expected returns. Rather, they focus directly on their importance in a model for the conditional betas over time. The tests therefore provide direct evidence in support of the argument of Ferson and Harvey (1993) about beta determination.

Given that grouping the attributes may obscure information we also examine $t$-tests for the importance of the individual attributes in the models for conditional betas. (These results are not reported in the tables to save space.) Certain attributes are easily excluded from the models for beta: the dividend yield, momentum, volatility, country credit rating and relative GDP do not appear to be useful for modelling the world market betas. In contrast, the priceto-book ratio is strongly related to the world market betas, in both the single and two-factor models. This is evidence that "value" investing, based on bookto-market ratios at the country level, has implications for global risk exposure. On the basis of these tests the following three variables emerge as the leading country-specific attributes, and we use these in our models for the world market betas: the price-to-book ratio, the relative inflation measure and the long term interest rate. ${ }^{13}$

The most important variables in the exchange beta models, based on the frequency of large $t$ ratios, are the country credit rating and the relative inflation measure. We use these variables in our models for the exchange risk betas.

\subsection{Are the attributes related to alpha?}

Table 3 summarizes the results of estimating the model of Eq. (4). To reduce the number of parameters in the model, we use information from the tests of Table 2. We simplify the model of the conditional betas by leaving out the lagged world instruments and selected country attributes, as described in the last section. We allow the conditional alphas to depend on the full set of variables, and we conduct tests to see which of the attributes are important for the alphas.

In Panel A of Table 3 we report exclusion tests for groups of the attributes in the alphas for each country, based on the two-factor asset pricing model

\footnotetext{
${ }^{13}$ While the term structure measure is marginally significant, it may roughly proxy for the difference between the long term interest rate and the relative inflation variable. If we err on the side of parsimony and leave important variables out of our beta models, then it biases our results in favor of finding that the variables enter through the alpha. We conduct some sensitivity checks on this issue, described below.
} 


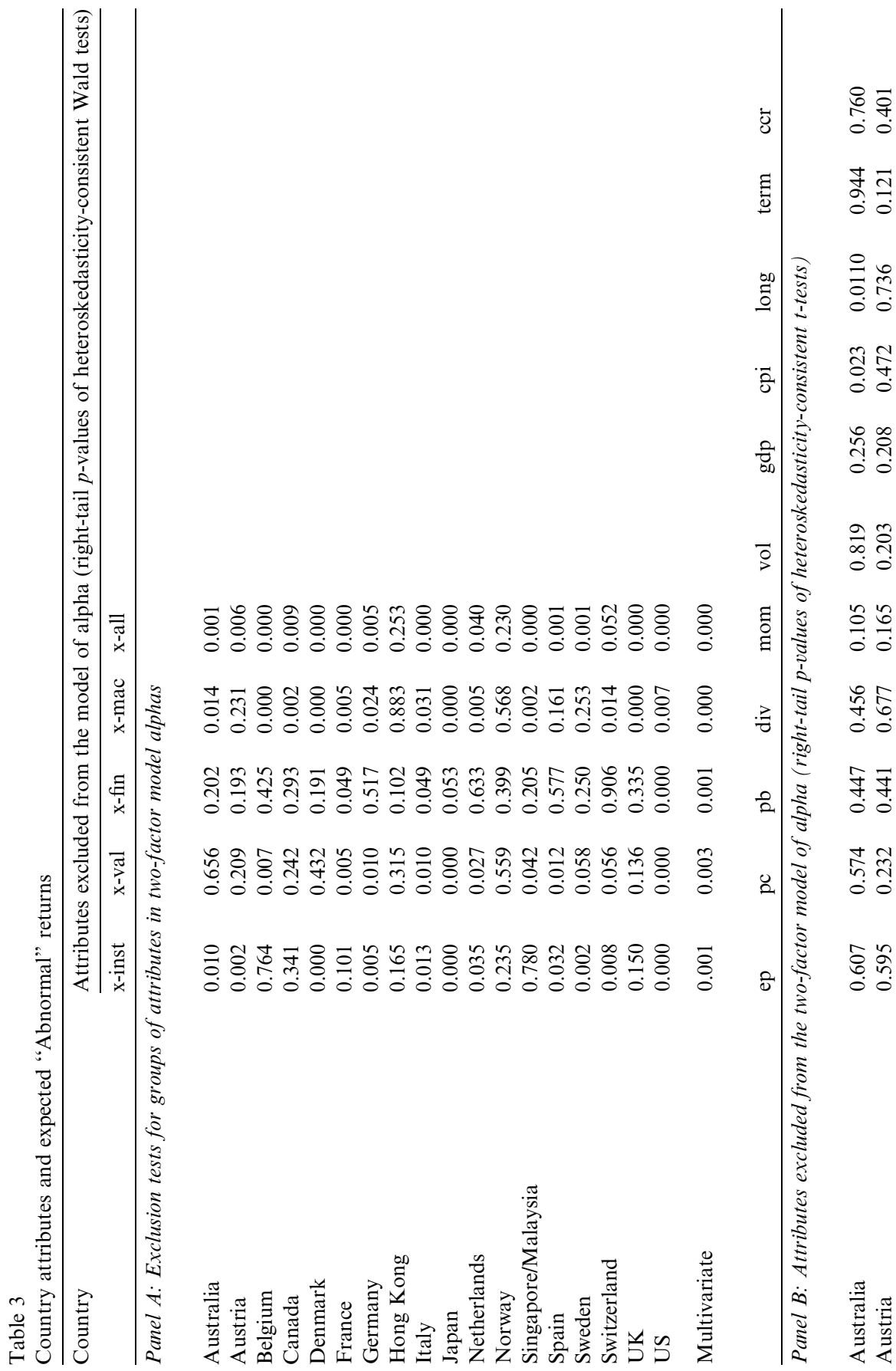




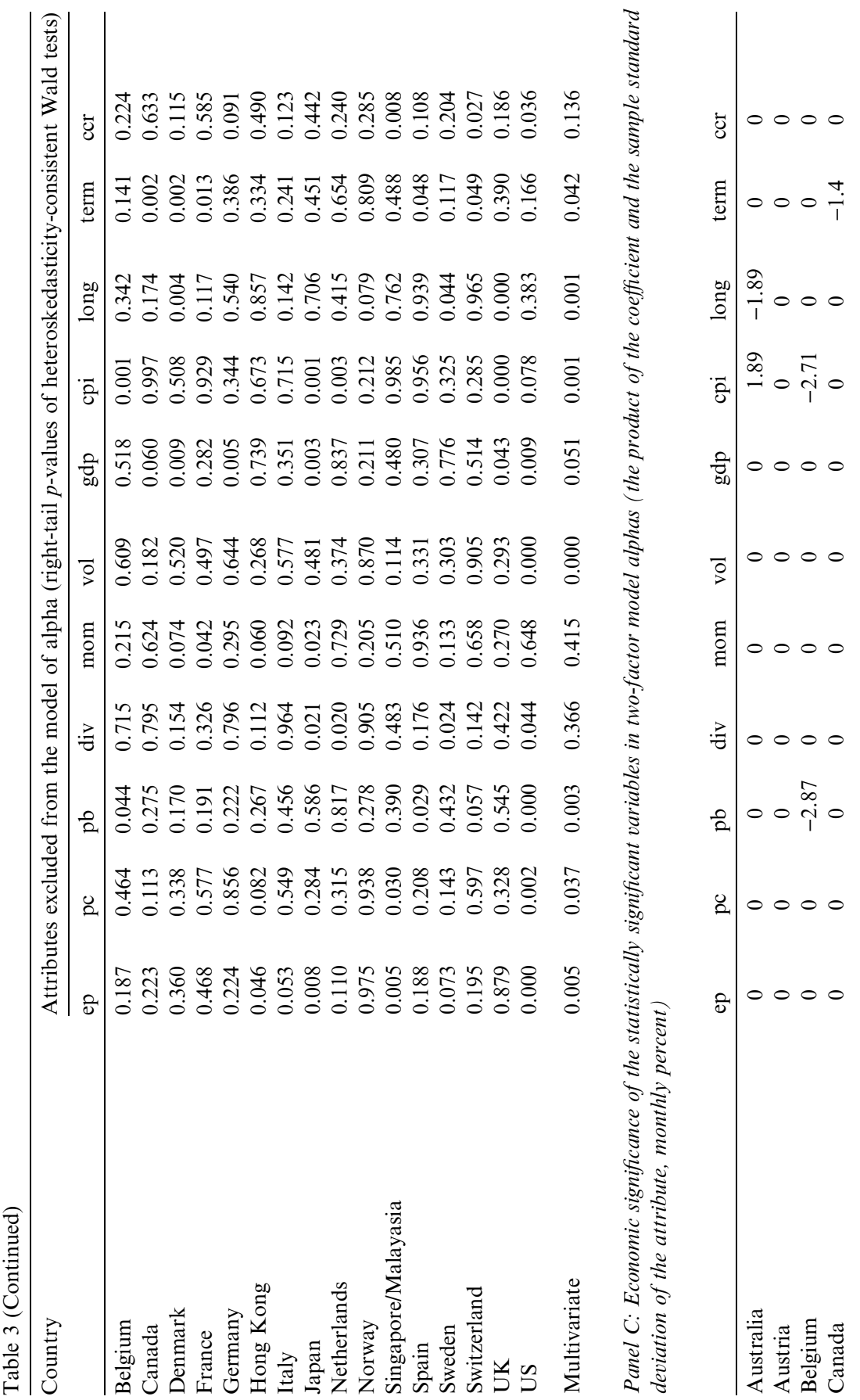




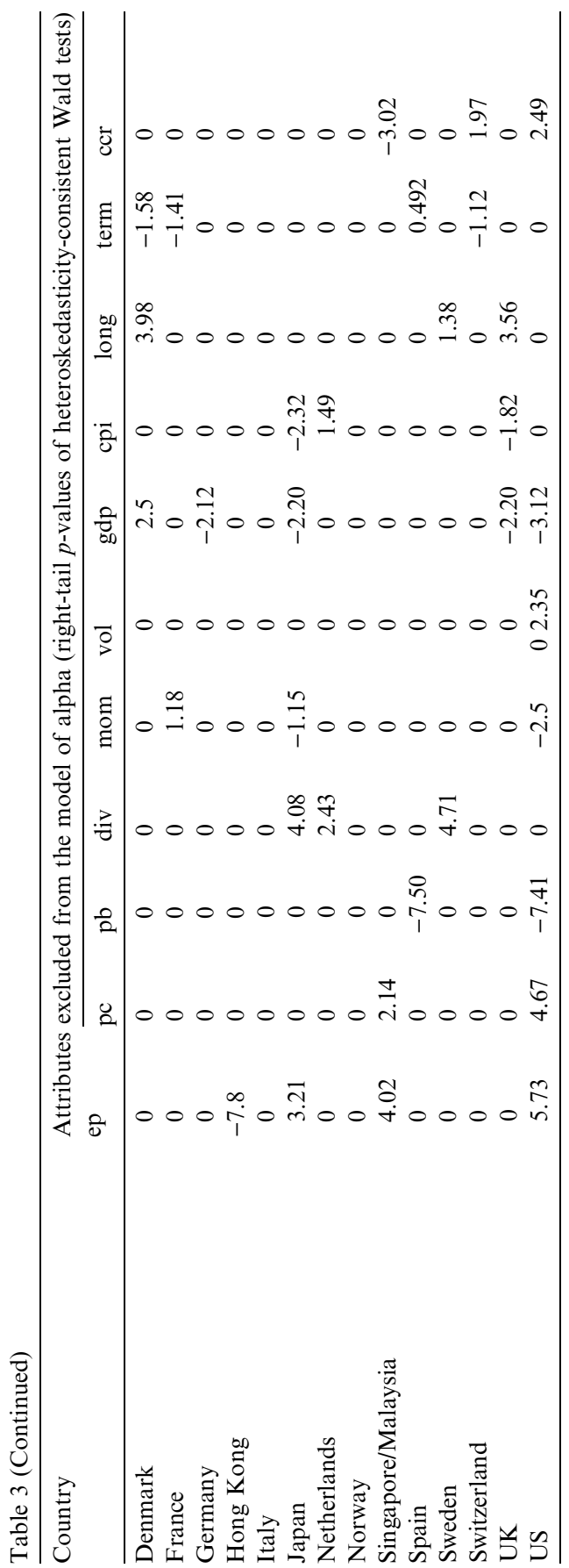


(three countries are excluded due to limited data). We find striking evidence of time-varying alphas. The joint tests of exclusion across all of the country attributes (x-all) produce $p$-values less than 0.05 for all except three countries: Hong Kong, Switzerland and Norway. Furthermore, each of the groups of attributes is jointly significant across the countries. The results are similar in the one-factor asset pricing model (not reported in the table). These tests present striking evidence of statistically significant predictable time-variation in returns that is correlated with the country attributes, and not subsumed by the conditional betas or the two global factor premiums.

We conducted some experiments to assess the sensitivity of these results to the set of attributes excluded from our models for the conditional betas. We allowed the world market betas to include the term structure variable and we substituted the volatility attribute for the relative inflation measure in the exchange risk betas. The results for the alphas in Table 3 were very similar.

Panel B of Table 3 reports the right-tail $p$-values for the individual attributes, testing which attributes may be excluded from the alphas relative to the two-factor asset pricing model. Seven of the 11 attributes are jointly significant across the countries: the earnings-to-price ratio, price-to-cash, priceto-book, volatility, relative cpi, long term interest rate and the term spread. The other four attributes provide no evidence that they are useful for predicting alpha. The significance of the volatility variables is driven entirely by its importance in the US, and the price-to-book ratio is driven mainly by the US.

The first two panels of Table 3 suggest that a number of attributes may be useful predictors of alpha relative to the two-factor model. However, it may be that the significance of these results reflects the precision of the estimates; i.e., small standard errors. Note that there were more significant attributes for the US (seven) and Japan (five) than for any other countries. The US and Japan produce relatively high $R$-squares in the regressions used in Table 3, which suggests that statistical precision should be higher for these countries. Given that the US and Japan are among the most efficient equity markets, it is reasonable to consider that the results may reflect statistical precision as opposed to trading opportunities.

Panel $\mathrm{C}$ provides some information about the economic magnitudes of the effects on alpha. We take the cases from Panel B where the $p$-value was less than 0.05 , and we report the product of the coefficient estimate in the alpha model with the sample standard deviation of the attribute over time. The result may be interpreted as the expected "abnormal" return response associated with a one standard deviation change in the attribute over time. The numbers are scaled to represent the return as percent per month. Out of 198 cases in the table (18 countries $\times 11$ attributes) there are 38 cases where the $p$ values are less than 0.05 , which is more than expected for the hypothesis that the appearance of attributes in the alphas is purely random. The estimates of the expected 
return per one standard deviation change in the attribute range from $-7.8 \%$ per month to $+5.73 \%$ per month, and most are in the neighbourhood of $1-2 \%$ per month. The standard deviations of the returns themselves are on the order of $5 \%$ per month.

The results so far show that the predetermined attribute data represent powerful information for international conditional asset pricing models. The variables are sufficiently informative about global equity market and exchange risk exposures to subsume a standard set of instruments for the state of the global economy in modelling these risk exposures. Certain attributes, such as the price-to-book ratio, are clearly related to risk at the country level. The lagged attributes are informative about the time-series of future returns, even after controlling for the world market and exchange risk betas and the associated factor returns. The attributes signal "abnormal" returns relative to the conditional two-factor model, which appear to be of economically significant magnitudes. These results should stimulate future research on the specification of international asset pricing models.

\subsection{Cross-sectional models revisited}

The results of the previous sections show that the relation between risk, expected returns and fundamental attributes - such as price-to-book and related ratios - is not generally the same across countries. Therefore, cross-sectional regression models which assume that such relations are captured by a fixed parameter, as in Eq. (3), are misspecified. Table 4 provides an illustration which suggests the empirical importance of the misspecification.

Table 4 summarizes cross-sectional predictive regressions of the country returns on the predetermined attributes and on versions of the attributes scaled to allow their relation to alpha or beta to differ across countries. The simplest example focuses on the information in a specific attribute about beta or alpha. We use a two-step approach. In the first step, for each country and attribute, the following time-series regression is estimated using the 60 months of data prior to each month $t$ :

$$
r_{i \tau+1}=\left(\alpha_{0 i}+\alpha_{1 i} A_{i \tau}\right)+\left(b_{0 i}+b_{1 i} A_{i \tau}\right) r_{\mathrm{m} \tau+1}+u_{i \tau+1}, \quad \tau=t-60, \ldots, t-1,
$$

where $A_{i \tau}$ is a fundamental attribute for country $i$ in month $\tau$. The coefficients $b_{1 i}$ and $\alpha_{1 i}$ represent the sensitivity (partial derivative) of the conditional beta and conditional alpha for country $i$ with respect to the value of attribute $A_{i}$, when the betas and expected returns are conditioned on the value of the attribute.

In the second step, we use the estimates of the coefficients $\alpha_{1 i}$ and $b_{1 i}$ to scale the attributes in a cross-sectional regression for month $t+1$ :

$$
r_{i t+1}=\gamma_{0, t+1}+\gamma_{1, t+1} A_{i t}+\gamma_{2, t+1} \alpha_{1 i} A_{i t}+\gamma_{3, t+1} b_{1 i} A_{i t}+e_{i t+1} ; \quad i=1, \ldots, N,
$$




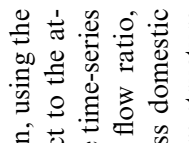

过菦

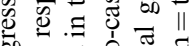
西要

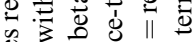

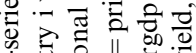

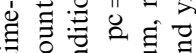
过

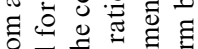
웜 उ 过 के

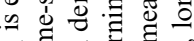

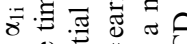
节焉 을

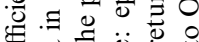

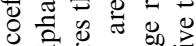
可苛苛

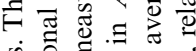

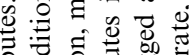
记 80 娄

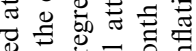

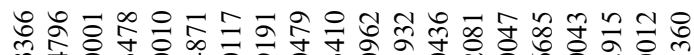

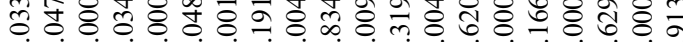

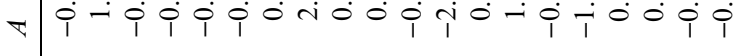

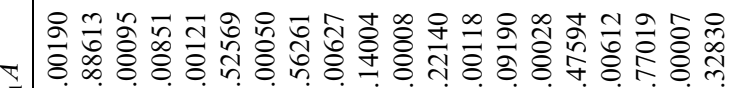
i

অ

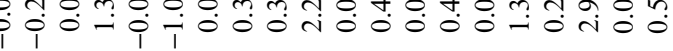

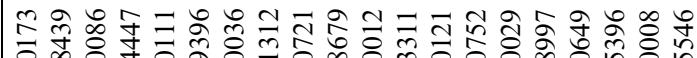

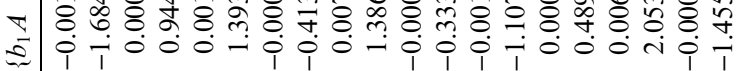

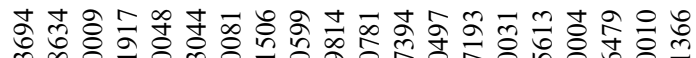

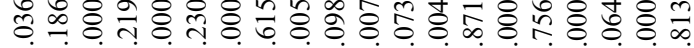

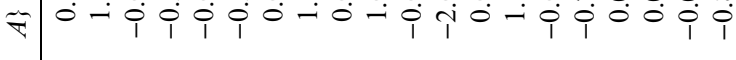

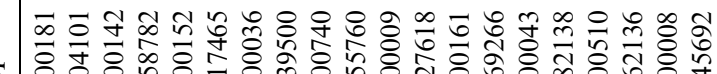
$\$$ \& व \&

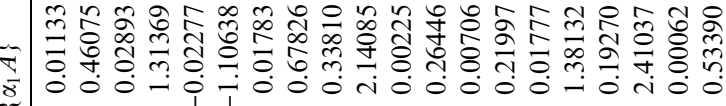
$\sim$

든

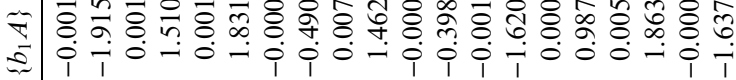
س $\underset{\nabla}{\sim}$

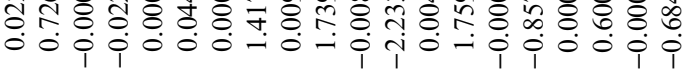

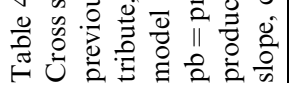

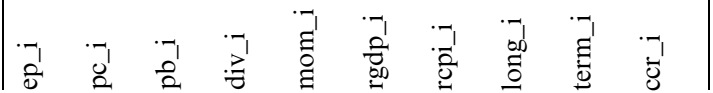


where $\gamma_{0, t+1}$ is the intercept and $\left(\gamma_{1, t+1}, \gamma_{2, t+1}, \gamma_{3, t+1}\right)$ are slope coefficients and $A_{i t}$ a fundamental attribute for country $i$ in month $t$. The dating convention indicates that the regressors are known at time $t$. When a single regressor is indicated in braces, e.g. $\{A\}$, the results describe univariate regressions. When there are two regressors in braces, e.g. $\left\{b_{1} A, A\right\}$, the results of a bivariate regression are shown. When there are three, e.g. $\left\{b_{1} A, A, \alpha_{1} A\right\}$, all three regressors are used. The time-series averages of the cross-sectional slope coefficients are shown, along with the Fama and MacBeth (1973) $t$ ratios for the hypothesis that the expected slope coefficient is zero.

Table 4 shows that scaling the attributes has a dramatic effect on the crosssectional regressions. For example, the $t$-ratio of the price-to-book ratio changes from less than 0.05 in its raw form to 1.83 (2.17 in a bivariate regression) when scaled to reflect the world market beta. Given that the relation between the attributes and the betas and alphas is likely to differ across countries, the scaled attributes should provide less noisy measures than the raw attributes in a cross-sectional analysis. This provides a simple illustration of how crosssectional factor models can be combined across countries. By scaling the attributes with the country-specific time-series coefficients, the attributes are measured in units that mean roughly the same thing across countries.

It is interesting to consider the effects of this scaling, or risk exposure adjustment in the two-factor model. Table 5, therefore summarizes the explanatory power of cross-sectional regressions that focus on a single attribute at a time. We first estimate regression (7) using 60 months of prior returns:

$$
r_{i \tau+1}=\left(\alpha_{0 i}+\alpha_{1 i} A_{i \tau}\right)+\left(b_{0 i}+A_{i \tau} b_{1 i}\right)^{\prime} r_{\mathrm{w} \tau+1}+u_{i \tau+1}, \quad \tau=t-60, \ldots, t-1,
$$

where $A_{i \hat{\tau}}$ is a fundamental attribute for country $i$ in month $\tau, r_{\mathrm{w}, \tau+1}$ is a twovector containing the world market and the exchange risk factor excess returns, and $b_{0 i}$ and $b_{1 i}$ are two-vectors of parameters. We use the fitted values of the alpha, $\left(\alpha_{0 i}+\alpha_{1 i} A_{i t-1}\right)$ and the conditional betas, $\left(b_{0 i}+b_{1 i} A_{i t-1}\right)$ in a cross-sectional regressions for the next month, $t$. Thus, the models use two risk factors and are conditional on a single lagged attribute.

We estimate the cross-sectional regressions using both OLS and WLS, where the weights for WLS are the standard errors from the first step, time-series regression. Given recent evidence that GLS is more reliable in cross-sectional regressions, Table 5 reports the time-series average of the adjusted $R$-squares from WLS models, although the OLS results are similar. ${ }^{14}$ Panel A covers the full sample period, while panels $\mathrm{B}$ and $\mathrm{C}$ break the sample into two equal subperi-

\footnotetext{
${ }^{14}$ See Kan and Zhang (1996) for recent simulation evidence on the reliability of GLS R-squares in cross-sectional regressions.
} 
Table 5

Cross-sectional explanatory power of lagged attributes in conditional betas and alphas (average adjusted R-squares). The results of estimating the cross-sectional regression model:

$r_{i t+1}=\gamma_{0, t+1}+\gamma_{1, t+1} \alpha_{i t}+\gamma_{2, t+1} \beta_{i t}+\gamma_{3, t+1} A_{i t}+e_{i t+1} ; \quad i=1, \ldots, N$

where $\gamma_{0, t+1}$ is the intercept and $\left(\gamma_{1, t+1}, \gamma_{2, t+1^{\prime}}, \gamma_{3, t+1}\right)$ are slope coefficients. The regressors are $\alpha_{i t}$, which is the fitted conditional alpha from a two-risk-factor model estimated from a time-series regression for country $i$ as a function of the lagged country-specific attribute, $A_{i t}$. $\beta_{i t}$ is a two-vector of conditional betas on the world market and exchange risk factor excess returns for country $i$, estimated from a time-series regression using 60 months of prior data. The dating convention indicates that the regressors are public information at time $t$. The cross-sectional regressions are estimated by weighted least squares, where the weights are the inverse of the standard errors from the first step time-series regressions. The individual attributes in $A_{i}$ are: ep $=$ earnings-to-price ratio, $\mathrm{pc}=$ priceto-cash flow ratio, $\mathrm{pb}=$ price-to-book-value ratio, $\mathrm{div}=$ dividend yield, $\mathrm{mom}=$ six-month lagged average return, a measure of momentum, $\operatorname{rgdp}=$ real gross domestic product measured relative to $\mathrm{OECD}, \mathrm{rcpi}=$ consumer price index inflation rate, relative to OECD, long = long term bond yield, term $=$ term structure slope, $\mathrm{ccr}=$ country credit risk measure

\begin{tabular}{ccc}
\hline Attribute & Alpha & Betas
\end{tabular}

\begin{tabular}{|c|c|c|c|c|}
\hline \multicolumn{5}{|c|}{ A. Full sample (January 1976-May 1993) } \\
\hline ep_i & 0.061 & 0.068 & 0.160 & 0.186 \\
\hline pc_i & 0.057 & 0.060 & 0.152 & 0.183 \\
\hline pb_i & 0.047 & 0.076 & 0.155 & 0.205 \\
\hline div_i & 0.036 & 0.064 & 0.164 & 0.186 \\
\hline mom_i & 0.093 & 0.067 & 0.178 & 0.201 \\
\hline rgdp_i & 0.062 & 0.067 & 0.171 & 0.199 \\
\hline rcpi_i & 0.059 & 0.070 & 0.177 & 0.197 \\
\hline long_i & 0.051 & 0.068 & 0.173 & 0.194 \\
\hline term_i & 0.059 & 0.067 & 0.182 & 0.211 \\
\hline ccr_i & 0.054 & 0.063 & 0.161 & 0.176 \\
\hline
\end{tabular}

B. First half (January 1976-March 1985)

$\begin{array}{lllll}\text { ep_i } & 0.014 & -0.006 & 0.132 & 0.130 \\ \text { pc_i } & 0.025 & 0.020 & 0.122 & 0.153 \\ \text { pb_i } & 0.019 & 0.076 & 0.157 & 0.219 \\ \text { div_i } & 0.004 & 0.046 & 0.180 & 0.199 \\ \text { mom_i } & 0.057 & -0.008 & 0.178 & 0.171 \\ \text { rgdp_i } & 0.032 & 0.031 & 0.219 & 0.240 \\ \text { rcpi_i } & 0.061 & 0.046 & 0.172 & 0.218 \\ \text { long_i } & -0.009 & 0.005 & 0.152 & 0.169 \\ \text { term_i } & 0.061 & 0.019 & 0.152 & 0.206 \\ \text { ccr_i } & 0.050 & 0.027 & 0.160 & 0.134\end{array}$

B. Second half (April 1985-May 1993)

\begin{tabular}{lllll} 
ep_i & 0.068 & 0.079 & 0.164 & 0.194 \\
pc_i & 0.062 & 0.066 & 0.156 & 0.187 \\
pb_i & 0.052 & 0.075 & 0.155 & 0.203 \\
div_i & 0.041 & 0.066 & 0.161 & 0.184 \\
mom_i & 0.098 & 0.079 & 0.177 & 0.206 \\
rgdp_i & 0.067 & 0.073 & 0.164 & 0.193 \\
rcpi_i & 0.059 & 0.073 & 0.177 & 0.194 \\
long_i & 0.060 & 0.078 & 0.176 & 0.198 \\
term_i & 0.059 & 0.074 & 0.187 & 0.212 \\
ccr_i & 0.055 & 0.068 & 0.161 & 0.182 \\
\hline
\end{tabular}


ods. There is one row for each attribute. In the first column the raw attribute is the only regressor. In the second column the fitted alpha $\left(\alpha_{0 i}+\alpha_{1 i} A_{i t-1}\right)$ is used, in the third column the conditional betas are used and in the fourth column, both the alpha and the betas are used in a three-variable regression.

Table 5 contains a number of interesting results. The raw attributes alone produce low $R$-squares and most of their explanatory power is confined to the second half of the sample period. When the attributes enter through their role as instruments for alphas and betas in the fourth column, the $R$-squares are often an order of magnitude larger, with the typical average $R$-square about $20 \%$ in either subperiod. While the attributes have some explanatory power as instruments for mispricing and for risk, their explanatory power for risk is typically much greater. In 29 of 30 cases in Table 5, the adjusted $R$-square of the alphas as risk measures is larger than the $R$-square of the alphas as instruments for mispricing.

\subsection{Interpreting the evidence}

Taken together, the evidence in the preceding sections provides a set of stylized "facts" about global asset pricing. Traditional asset pricing models assuming well-functioning, integrated markets quite generally imply that expected returns are related to their covariances with a global stochastic discount factor. When the discount factor is a function of a set of global risk variables, such models imply the standard beta pricing paradigm used in this paper. According to this paradigm, anything that explains the cross-section of future asset returns must be related to the cross-sectional structure of the betas.

Table 3 models betas explicitly using time-series data, but no cross-sectional information. The tests say that the local country attributes subsume the global information variables, for modelling the betas on two risk factors. Table 4 goes further by observing that when the local attributes are adjusted to better reflect the cross-sectional structure of the betas, their cross-sectional explanatory power improves. Table 5 shows that while the attributes have some explanatory power as instruments for mispricing and for risk, their explanatory power for risk is typically much greater.

\section{Concluding remarks}

This paper analyses both the cross-section and the time-series of expected returns in 21 national equity markets, focussing on the role of fundamental attributes of these economies for models of country risk and expected returns. We study three types of attributes. The first group includes traditional valua- 
tion ratios such as price-to-book-value, cash-flow, earnings and dividends. The second group quantifies relative economic performance with measures such as relative GDP per capita, relative inflation, the term structure of interest rates and the long term interest rates.

By explicitly linking the predetermined attributes to global economic risk factors, we shed new light on the controversy over the extent to which variables like book-to-market can predict returns because they are proxies for risk. We employ a database of country returns and attributes that is free of some biases that plague studies using individual common stocks. We find that the predetermined attributes drive out a set of common global instrumental variables in models of conditional betas. The price-to-book-value ratio is strongly related to global stock market risk exposure.

Our empirical framework links the attribute analysis of investment practitioners, so-called composite modelling, to the asset pricing theory and factor modelling approach of academic studies. We believe that the two communities have much to learn from each other in this area, and such a link promotes a deeper understanding of the relevant issues from both perspectives. Our approach provides a way to combine factor models across countries. In doing so, one must adjust for the fact that the value of a variable like the price-toearnings ratio has a different economic meaning in different countries, due to differences in accounting conventions, dividend policies, etc. Our framework accounts for these differences, providing risk-exposure adjustments for the attributes in cross-sectional factor models. The same idea can be used to control for heterogeneity within a country, due to industry-related differences in accounting conventions, etc. Models like ours can also be used in future research to construct risk-adjusted returns, for example, in conducting event studies in samples of firms from different countries.

We find evidence that the relation of the fundamental attributes to expected stock returns and to risk is different across countries. Therefore, cross-sectional models which do not account for such differences are misspecified, and a simple correction by scaling the attributes of each country can improve the explanatory power.

Some of the attributes enter mainly as instruments for beta (e.g. earningsto-price, price-to-book) and some enter mainly as instruments for alpha (e.g. momentum), while others seem to capture a mix of the two. The cross-sectional explanatory power of the lagged attributes arises from both their role instruments for mispricing and for risk, but their explanatory power for risk is typically much greater. These results have strong implications for international asset allocation strategies, and present a challenge for the further development of conditional asset pricing models for international equity returns. 


\section{Acknowledgements}

We are grateful to Jeffrey Frankel, Richard Lyons, Bruce Lehmann, Brian McCulloch, Nejat Sehun for comments and we also appreciate the advice of Fred Fogg and Jaideep Khanna of Morgan Stanley on data issues. Early versions of paper were presented in workshops at Arizona State University, the 1994 Berkeley Program in Finance, the 1994 Quantec Investments Seminar, the 1995 Global Investment Management Conference in Geneva, the 1996 Global Investment Conference in Whisler, B.C. and the Seventh Annual (1996) Conference on Financial Economics and Accounting. Ferson acknowledges financial support from the Pigott-PACCAR professorship at the University of Washington. Harvey acknowledges financial support from a Batterymarch Fellowship.

\section{Appendix A}

This appendix describes our data and sources in more detail. IFS refers to International Financial Statistics. DataSt refers to Datastream, Ltd. OECD refers to the Organization for Economic Cooperation and Development.

\section{A.1. Valuation ratios}

Value-weighted price to earnings ratios are available from MSCI starting in January 1970 except for Austria (January 1977), Finland (January 1988), Italy (April 1984), Ireland (May 1990), New Zealand (January 1988), Singapore/Malaysia (December 1972), and Spain (January 1977). These are value-weighted averages of the ratios for the firms in the MSCI universe, based on the most recently available accounting data each month. Value-weighted price to cash earnings are defined as accounting earnings plus depreciation. These ratios are available beginning in January of 1970 except for Canada (December 1974), Finland (January 1988), France (September 1971), Hong Kong (December 1972), Ireland (May 1990), New Zealand (January 1988), Singapore/Malaysia (December 1972), Spain (September 1971), and Switzerland (January 1977). Value-weighted price-to-book-value ratios are available from January 1974 for all countries except Finland and New Zealand (both begin January 1988) and Ireland, which begins in May of 1990. Dividend yields are the 12 month moving sum of dividends divided by the current index level. The lagged value of the dividend yields is used. Dividend yields are available from January 1970 except for Finland and New Zealand (which both begin in January 1988), Hong Kong (January 1973), Ireland (May 1990) and Singapore/Malaysia (December 1972). 


\section{A.2. Macroeconomic attributes}

The ratio of lagged, GDP per capita, to lagged GDP per capita for the OECD countries is provided by the OECD, which provides quarterly OECD GDP figures for most of the countries. For some countries, the GDP data are only available on an annual basis. The ratio is lagged five quarters to account for publication lag. Since the data are observed quarterly (or annually), the monthly observations for each month in a quarter (or year) are the same. The population data are observed annually. The data sources and retrieval codes for the GDP data are listed in Table 6.

To obtain the measures of GDP per capita, the country GDP measures are divided by the following population series given in Table 7 .

Table 8 describes the currency exchange rate data used are used to convert GDP into local currency to US dollar terms. These series are national currency units per US dollar, quarterly and annual averages, depending on the frequency of the GDP data. Period averages are used to better match the fact that GDP figures also represent an average over the period as opposed to a spot figure.

The relative inflation measure is the ratio of annual percentage changes in the local Consumer price index to annual percentage changes in the OECD CPI inflation series, available monthly for most of the countries. In predictive regressions, the variable is lagged five quarters to account for publication lag. The inflation series and their access codes are as given in Table 9.

A long term interest rate is measured for each country as an annualized percentage rate. In the predictive regressions, the long term rate is lagged one month. For two countries Hong Kong and Singapore, data are not available, so a US rate was used. The sources and series codes are as given in Table 10.

Short term interest rates for the various countries are used to construct a measure of the slope of the term structure. The term spread is the difference between the long term interest rate and a short term interest rate in each country. The term spread is lagged one month in the predictive regressions. The short term interest rates are listed here together with their series codes (Table 11).

\section{A.3. World information variables}

A short term slope of the term structure is the difference between the 90-day Eurodollar rate (Citibase FYUR3M) and the 30-day Eurodollar deposit rate. The short term interest rate is the 30-day Eurodollar deposit yield. Both are monthly averages of daily quotes. The lagged values of the MSCI world stock market return, the dividend yield of the world stock market index, and the G10 FX return are also used. 
Table 6

Data sources for GDP data

\begin{tabular}{|c|c|c|c|c|}
\hline Country & Period & Frequency & Source & Code \\
\hline AUS & 1960Q1-1992Q4 & Quarter & IFS & 19399B.CZF... \\
\hline \multirow[t]{2}{*}{ AUT } & 1960Q1-1963Q4 & Annual & IFS & 12299B..ZF... \\
\hline & 1964Q1-1992Q4 & Quarter & OECD & OE020000A \\
\hline \multirow[t]{2}{*}{ BEL } & 1960Q1-1969Q4 & Annual & IFS & 12499B..ZF... \\
\hline & 1970Q1-1992Q4 & Annual & OECD & BGGDPCR. \\
\hline CAN & 1960Q1-1992Q4 & Quarter & IFS & 15699B.CZF \\
\hline \multirow[t]{2}{*}{ DEN } & 1960Q1-1986Q4 & Annual & IFS & 12899B..ZF... \\
\hline & 1987Q1-1992Q4 & Quarter & IFS & 12899B..ZF ... \\
\hline \multirow[t]{3}{*}{ FIN } & 1960Q1-1964Q4 & Annual & IFS & 17299B..ZF... \\
\hline & 1965Q1-1969Q4 & Quarter & IMF & FNI99B..A \\
\hline & 1970Q1-1992Q4 & Quarter & IFS & 17299B..ZF... \\
\hline \multirow[t]{3}{*}{ FRA } & 1960Q1-1964Q4 & Annual & IFS & 13299B.CZF... \\
\hline & 1965Q1-1969Q4 & Quarter & IFS & 13299B.CZF... \\
\hline & 1970Q1-1992Q4 & Quarter & OECD & FR104000B \\
\hline GER & 1960Q1-1992Q4 & Quarter & IFS & 13499A.CZF... \\
\hline HKG & 1960Q1-1992Q5 & Annual & DataSt & HKEXTOTL \\
\hline \multirow[t]{2}{*}{ IRE } & 1960Q1-1969Q4 & Annual & IFS & 17899B..ZF... \\
\hline & 1970Q1-1970Q4 & Annual & OECD & IRGDPCR. \\
\hline \multirow[t]{2}{*}{ ITA } & 1960Q1-1987Q4 & Quarter & IFS & 13699B.CZF... \\
\hline & 1988Q1-1992Q4 & Quarter & OECD & IT301000B \\
\hline JAP & 1960Q1-1992Q4 & Quarter & IFS & 15899B.CZF... \\
\hline \multirow[t]{2}{*}{$\mathrm{HOL}$} & 1960Q1-1976Q4 & Annual & IFS & 13899B.CZF... \\
\hline & 1977Q1-1992Q4 & Quarter & OECD & NL201000B \\
\hline \multirow[t]{2}{*}{ NZL } & 1960Q1-1969Q4 & Annual & IFS & 19699B..ZF... \\
\hline & 1970Q1-1992Q4 & Annual & OECD & NZGDPCR. \\
\hline \multirow[t]{6}{*}{ NOR } & 1960Q1-1960Q4 & Annual & IFS & 14299B..ZF... \\
\hline & 1961Q1-1970Q4 & Quarter & IFS & 14299B..ZF... \\
\hline & 1971Q1-1977Q4 & Annual & IFS & 14299B..ZF... \\
\hline & 1978Q1-1986Q3 & Quarter & IFS & 14299B..ZF... \\
\hline & 1986Q4 & Annual & IFS & 14299B..ZF... \\
\hline & 1987Q1-1993Q1 & Quarter & IFS & 14299B..ZF... \\
\hline SNG & 1960Q1-1992Q4 & Annual & IFS & 57699B..ZF... \\
\hline \multirow[t]{2}{*}{ SPA } & 1960Q1-1969Q4 & Annual & IFS & 18499B..ZF... \\
\hline & 1970Q1-1992Q4 & Annual & OECD & ESGDPCR. \\
\hline \multirow[t]{2}{*}{ SWE } & 1960Q1-1979Q4 & Annual & IFS & 14499B..ZF... \\
\hline & 1980Q1-1992Q4 & Quarter & IFS & 14499B..ZF... \\
\hline \multirow[t]{3}{*}{ SWI } & 1960Q1-1966Q4 & Annual & IFS & 14699B.CZF... \\
\hline & 1967Q1-1969Q4 & Quarter & IMF & SWI99B..A \\
\hline & 1970Q1-1993Q1 & Quarter & IFS & 14699B.CZF... \\
\hline GBR & 1960Q1-1992Q4 & Quarter & IFS & 11299B.CZF... \\
\hline USA & 1960Q1-1993Q1 & Quarter & IFS & 11199B.CZF... \\
\hline WRD & 1960Q1-1992Q4 & Quarter & OECD & OC001000B \\
\hline
\end{tabular}

\section{A.4. Global risk factors}

Data are available as early as January of 1970 for some of the series; all are available by February of 1971. The MSCI world return is the US dollar world 
Table 7

Data sources for population data

\begin{tabular}{lllll}
\hline Country & Period & Frequency & Source & Code \\
\hline AUS & 1960 Q1-1992Q4 & Annual & IFS & $19399 Z . . Z F \ldots$ \\
AUT & $1960 Q 1-1992 Q 4$ & Annual & IFS & $12299 Z . . Z F \ldots$ \\
BEL & $1960 Q 1-1992 Q 4$ & Annual & IFS & $12499 Z . . Z F \ldots$ \\
CAN & $1960 Q 1-1992 Q 4$ & Annual & IFS & $15699 Z . . Z F \ldots$ \\
DEN & $1960 Q 1-1992 Q 4$ & Annual & IFS & $12899 Z . . Z F \ldots$ \\
FIN & $1960 Q 1-1992 Q 4$ & Annual & IFS & $17299 Z . . Z F \ldots$ \\
FRA & $1960 Q 1-1992 Q 4$ & Annual & IFS & $13299 Z . . Z F \ldots$ \\
GER & $1960 Q 1-1992 Q 4$ & Annual & IFS & $13499 Z . . Z F \ldots$ \\
HKG & $1973 Q 4-1992 Q 4$ & Annual & DataSt & HKTOTPOP \\
IRE & $1960 Q 1-1992 Q 4$ & Annual & IFS & $17899 Z . . Z F \ldots$ \\
ITA & $1960 Q 1-1992 Q 4$ & Annual & IFS & $13699 Z . . Z F \ldots$ \\
JAP & $1960 Q 1-1992 Q 4$ & Annual & IFS & $15899 Z . . Z F \ldots$ \\
HOL & $1960 Q 1-1992 Q 4$ & Annual & IFS & $13899 Z . . Z F \ldots$ \\
NZL & $1960 Q 1-1992 Q 4$ & Annual & IFS & $19699 Z . . Z F \ldots$ \\
NOR & $1960 Q 1-1992 Q 4$ & Annual & IFS & $14299 Z . . Z F \ldots$ \\
SNG & $1960 Q 1-1992 Q 4$ & Annual & IFS & $57699 Z . . Z F \ldots$ \\
SPA & $1960 Q 1-1992 Q 4$ & Annual & IFS & $18499 Z . . Z F \ldots$ \\
SWE & $1960 Q 1-1992 Q 4$ & Annual & IFS & $14499 Z . . Z F \ldots$ \\
SWI & $1960 Q 1-1992 Q 4$ & Annual & IFS & $14699 Z . . Z F \ldots$ \\
GBR & $1960 Q 1-1992 Q 4$ & Annual & IFS & $11299 Z . . Z F \ldots$ \\
USA & $1960 Q 1-1992 Q 4$ & Annual & IFS & $11199 Z . . Z F \ldots$ \\
WRD & $1969 Q 4-1992 Q 4$ & Annual & OECD & OCDTOTPP \\
& $1973 Q 4-1992 Q 4$ & Annual & DataSt & WDTOTPOP \\
\hline & & & & \\
\hline
\end{tabular}

Table 8

Data sources for interest rate data

\begin{tabular}{|c|c|}
\hline Country & Code \\
\hline AUS & Market rate $193 . . R F . Z F \ldots$ \\
\hline AUT & Official rate $122 . . R F . Z F \ldots$ \\
\hline BEL & Market rate $124 . . \mathrm{RF} . \mathrm{ZF} \ldots$ \\
\hline CAN & Market rate $156 .$. RF.ZF... \\
\hline DEN & Market rate $128 . . R F . Z F \ldots$ \\
\hline FIN & Official rate $172 . . R F . Z F .$. \\
\hline FRA & Official rate $132 . . R F . Z F \ldots$ \\
\hline GER & Market rate $134 . . R F . Z F \ldots$ \\
\hline HKG & Market rate $532 . . \mathrm{RF} . \mathrm{ZF} \ldots$ \\
\hline IRE & Market rate $178 .$. RF.ZF... \\
\hline ITA & Market rate $136 .$. RF.ZF... \\
\hline JAP & Market rate $158 .$. RF.ZF... \\
\hline $\mathrm{HOL}$ & Market rate $138 . . R F . Z F \ldots$ \\
\hline NZL & Market rate $196 .$. RF.ZF... \\
\hline NOR & Official rate $142 . . \mathrm{RF} . \mathrm{ZF} \ldots$ \\
\hline $\mathrm{SNG}$ & Market rate $576 .$. RF.ZF... \\
\hline SPA & Market rate $184 . . \mathrm{RF} . \mathrm{ZF} \ldots$ \\
\hline SWE & Official rate $144 . . R F . Z F \ldots$ \\
\hline SWI & Official rate $146 . . R F . Z F \ldots$ \\
\hline GBR & Market rate $112 .$. RF.ZF... \\
\hline
\end{tabular}


Table 9

Data sources for inflation data

\begin{tabular}{|c|c|c|c|c|}
\hline Country & Period & Frequency & Source & Code \\
\hline AUS & 1957Q1-1993Q1 & Quarter & IFS & $19364 \ldots Z F \ldots$ \\
\hline AUT & 1957 Jan-1993 Apr & Month & IFS & $12264 \ldots Z F \ldots$ \\
\hline BEL & 1957 Jan-1993 May & Month & IFS & $12464 \ldots Z F \ldots$ \\
\hline CAN & 1957 Jan-1993 Apr & Month & IFS & $15664 \ldots Z F \ldots$ \\
\hline \multirow[t]{2}{*}{ DEN } & 1957Q1-1966Q4 & Quarter & IFS & $12864 \ldots \mathrm{ZF} \ldots$ \\
\hline & 1967 Jan-1993 Mar & Month & IFS & $12864 \ldots Z F \ldots$ \\
\hline FIN & 1957 Jan-1993 Apr & Month & IFS & $17264 \ldots Z F \ldots$ \\
\hline FRA & 1957 Jan-1993 May & Month & IFS & $13264 \ldots Z F \ldots$ \\
\hline GER & 1957 Jan-1993 Apr & Month & IFS & $13464 \ldots Z F \ldots$ \\
\hline HKG & 1969 Mar-1993 Feb & Month & IFS & $53264 \ldots Z F \ldots$ \\
\hline \multirow[t]{2}{*}{ IRE } & 1957Q1-1993Q1 & Quarter & IFS & $17864 \ldots Z F \ldots$ \\
\hline & 1969Q4-1993Q2 & Quarter & OECD & IROCPCONF \\
\hline ITA & 1957 Jan-1992 Oct & Month & IFS & $13664 \ldots Z F \ldots$ \\
\hline JAP & 1957 Jan-1993 Apr & Month & IFS & $15864 \ldots Z F \ldots$ \\
\hline HOL & 1957 Jan-1993 Mar & Month & IFS & $13864 \ldots Z F \ldots$ \\
\hline NZL & 1957Q1-1993Q1 & Quarter & IFS & $19664 \ldots Z F \ldots$ \\
\hline NOR & 1957 Jan-1993 Apr & Month & IFS & $14264 \ldots Z F \ldots$ \\
\hline SNG & 1968 Jan-1993 Apr & Month & IFS & $57664 \ldots \mathrm{ZF} \ldots$ \\
\hline SPA & 1957 Jan-1993 Apr & Month & IFS & $18464 \ldots Z F \ldots$ \\
\hline SWE & 1957 Jan-1993 Mar & Month & IFS & $14464 \ldots Z F \ldots$ \\
\hline SWI & 1957 Jan-1993 May & Month & IFS & $14664 \ldots Z F \ldots$ \\
\hline GBR & 1957 Jan-1993 Feb & Month & IFS & $11264 \ldots Z F \ldots$ \\
\hline USA & 1957 Jan-1993 May & Month & IFS & $11164 \ldots Z F \ldots$ \\
\hline WRD & 1957 Jan-1992 Dec & Month & IFS & $00164 \ldots Z F \ldots$ \\
\hline
\end{tabular}

market return less the 30-day Eurodollar rate. This series is from DATASTREAM. The G10 FX return is the return on holding a portfolio of currencies of the G10 countries (plus Switzerland) in excess of the 30-day Eurodollar rate. The currency return is the percentage change in the spot exchange rate plus the local currency, 30-day Eurodeposit rate. The portfolio weights are based on a one-year lag of a five-year moving average of trade sector weights. The numerator of the weight is the sum of the imports plus exports and the denominator is the sum over the countries, of the imports plus exports of each country, measured in a common currency (US dollars). We use a five-year moving average of these weights, lagged by one year to insure they are predetermined, public information. Further details of the index construction are presented in Harvey (1993b), who compares this measure with the Federal Reserve series of G10 Exchange rate changes that was used by Ferson and Harvey $(1993,1994 a, b)$. He finds that the correlation of the two series is in excess of 0.9. In our sample, the correlation between the MSCI world index and the G10FX index is 0.36 . 


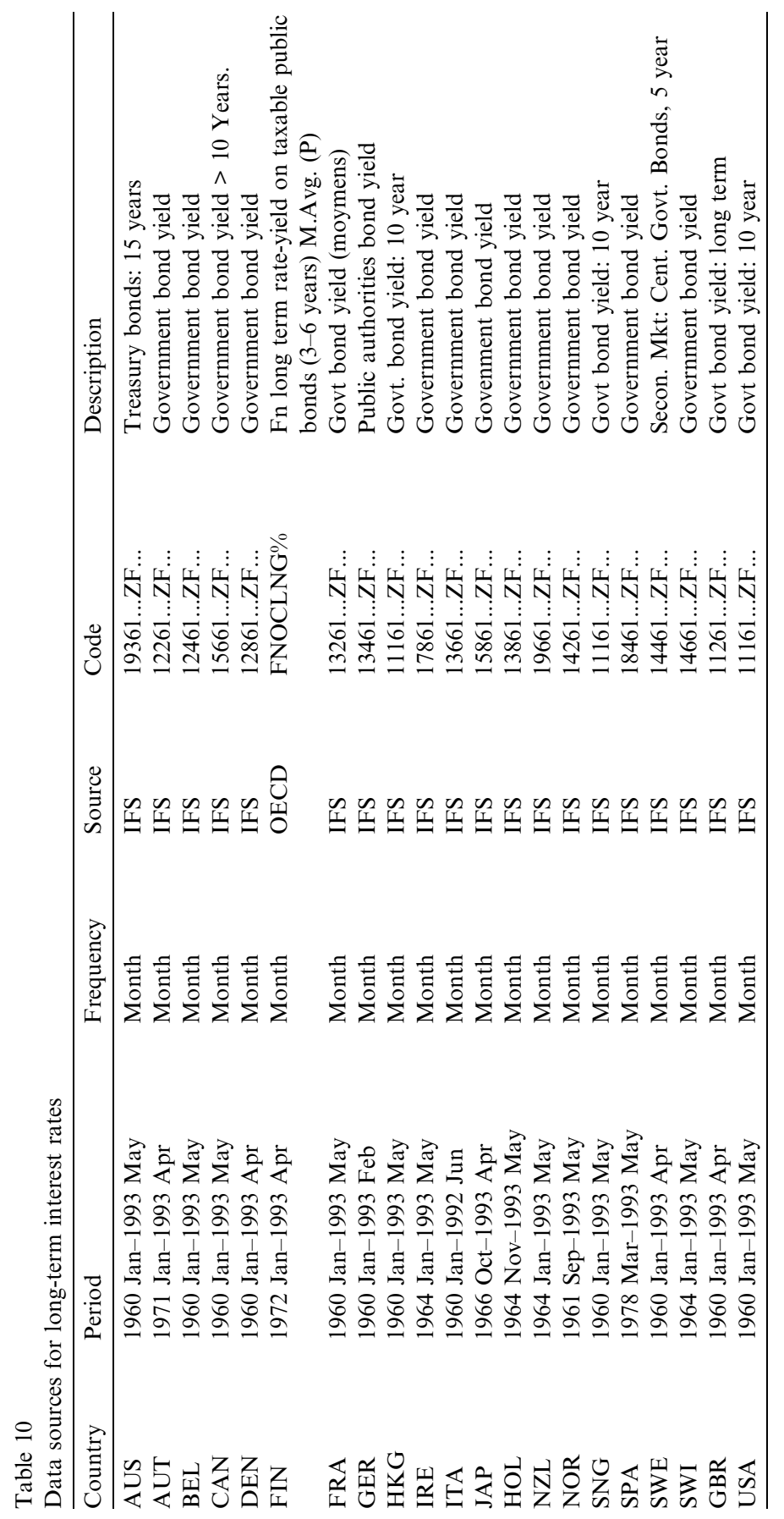




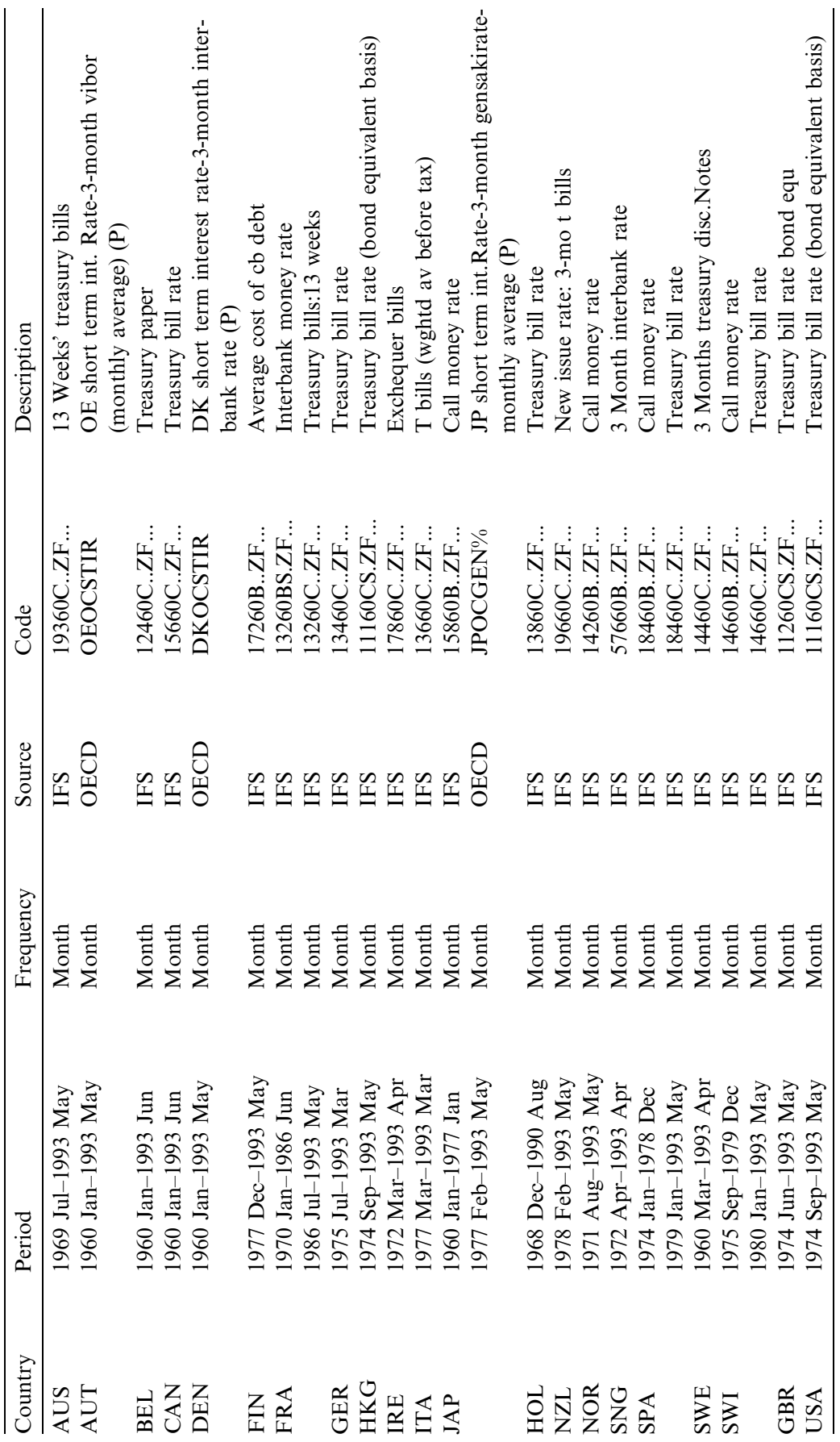




\section{References}

Adler, M., Dumas, B., 1983. International portfolio selection and corporation finance: A synthesis. Journal of Finance 38, 925-984.

Ando, A., Auerbach, A.J., 1990. Cost of capital in Japan. Journal of the Japanese and International Economies 4, 323-350.

Basu, S., 1977. The investment performance of common stocks in relation to their price-earnings ratios: A test of the efficient markets hypothesis. Journal of Finance 32, 663-682.

Berk, J.B., 1995. A critique of size-related anomalies. Review of Financial Studies 8, 275-286.

Black, F., 1993. Beta and return. Journal of Portfolio Management 20, 8-18.

Bodurtha, J.N., Cho, D.C., Senbet, L.W., 1989. Economic forces and the stock market: An international perspective. Global Finance Journal 1, 21-46.

Bollerslev, T.P., Engle, R.F., Wooldridge, J.M., 1988. A capital asset pricing model with timevarying covariances. Journal of Political Economy 96, 116-131.

Brennan, M.J., Chordia, T., Subrahmanyam, A., 1996. Cross-sectional Determinants of Expected Returns, Working Paper. University of California, Los Angeles.

Breen, W.J., Korajczyk, R.A., 1994. On selection biases in book-to-market based tests of asset pricing models. Working paper, Northwestern University.

Brown, S.J., Otsuki, T., 1990a. Macroeconomic factors and the Japanese equity markets: The CAPMD project, In: Elton, E.J., Gruber, M.J. (Eds.), Ch. 8, Japanese Capital Markets. Harper and Row, New York, pp. 175-192.

Brown, S.J., Otsuki, T., 1990b. A global asset pricing model. Working paper, New York University.

Capaul, C., Rowley, I., Sharpe, W., 1993. International value and growth stock returns. Financial Analysts Journal, 27-36.

Chan, L.K.C., Hamao, Y., Lakonishok, J., 1991. Fundamentals and stock returns in Japan. Journal of Finance 46 (5), 1739-1764.

Chan, L.K.C., Jegadeesh, N., Lakonishok, J., 1995. Evaluating the performance of value versus glamor stocks: The impact of selection bias. Journal of Financial Economics 38, $269-296$.

Chen, N.-F., Richard, R.R., Stephen, R.A., 1986. Economic forces and the stock market. Journal of Business 59, 383-403.

Christopherson, J.A., Tritton, D.Y., 1995. Equity style classification system, In: Coggin, T.D., Fabozzi, F.J. (Eds.), The Handbook of Equity Style Management, Frank J. Fabozzi Associates, New Hope, PA.

Conrad, J., Kaul, G., 1996. An anatomy of trading strategies. Working paper, University of North Carolina.

Dumas, B., Solnik, B., 1995. The world price of foreign exchange rate risk. Journal of Finance 50, 445-480.

Engel, C., Rodrigues, A., 1989. Tests of international CAPM with time-varying covariances.

Fama, E.F., French, K.R., 1992. The cross-section of expected returns. Journal of Finance 47, $427-$ 465.

Fama, E.F., French, K.R., 1993. Common risk factors in the returns on stocks and bonds. Journal of Financial Economics 33, 3-56.

Fama, E.F., French, K.R., 1996. Multifactor explanations of asset pricing anomalies. Journal of Finance 51, 55-87.

Fama, E.F., MacBeth, J.D., 1973. Risk, return and equilibrium: Empirical tests. Journal of Political Economy 81, 607-636.

Ferson, W.E., 1990. Are the latent variables in time-varying expected returns compensation for consumption risk? Journal of Finance 45, 397-430. 
Ferson, W.E., 1996. Warning: Attribute-sorted portfolios can be hazardous to your research, 1996. In: Saitou, S., Sawaki, K., Kubota, K. (Eds.), Modern Portfolio Theory and its Applications, Center for Academic Societies, Osaka Japan ISBN 4-906417-10-2 c3033 p6000E, pp. 21-32.

Ferson, W.E., Harvey, C.R., 1991. The variation of economic risk premiums. Journal of Political Economy 99, 385-415.

Ferson, W.E., Harvey, C.R., 1993. The risk and predictability of international equity returns. Review of Financial Studies 6, 527-566.

Ferson, W.E., Harvey, C.R., 1994a. Sources of risk and expected returns in international equity markets. Journal of Banking and Finance 18, 775-803.

Ferson, W.E., Harvey, C.R., 1994b. An exploratory investigation of the fundamental determinants of international equity market returns. In: Frankel, J.A. Internationalization of Equity Markets, University of Chicago Press (ISBN 0-226-26001-1), pp. 59-148.

Ferson, W.E., Kandel, S., Stambaugh, R.F., 1987. Tests of asset pricing with time-varying expected risk premiums and market beta. Journal of Finance 42, 201-220.

Frankel, J., 1982. In search of the exchange risk premium: A six currency test assuming mean variance optimization. Journal of International Money and Finance 1, 255-274.

Gibbons, M.R., Ferson, W.E., 1985. Tests of asset pricing models with changing expectations and an unobservable market portfolio. Journal of Financial Economics 14, 217-236.

Giovannini, A., Jorion, P., 1987. Interest rates and risk premia in the stock market and in the foreign exchange market. Journal of International Money and Finance 6, 107-123.

Giovannini, A., Jorion, P., 1989. Time variation of risk and return in the foreign exchange and stock markets. Journal of Finance 44, 307-325.

Graham, B., Dodd, D., 1934. Security analysis. McGraw-Hill, New York.

Guerard, J.B., Takano, M., 1990. Composite modelling in the Japanese equity markets. Working paper presented at the Berkeley program in Finance.

Hamao, Y., 1988. An empirical examination of arbitrage pricing theory: Using Japanese data. Japan and the World Economy 1, 45-61.

Hansen, L.P., 1982. Large sample properties of the generalized method of moments estimators. Econometrica 50, 1029-1054.

Hansen, L.P., Hodrick, R.J., 1983. Risk averse speculation in forward foreign exchange markets: An econometric analysis of linear models. In: Frenkel, J.A. (Ed.), Exchange Rates and International Macroeconomics. University of Chicago Press, Chicago, IL, pp. 113-152.

Hansen, L.P., Singleton, K., 1983. Stochastic consumption, risk aversion, and the temporal behavior of asset returns. Journal of Political Economy 91, 249-265.

Harris, T.C., Opler, T.C., 1990. Stock market returns and real activity. Working paper, University of Chicago Press, UCLA.

Haugen, R.A., Baker, N.L., 1996. Commonality in the determinants of expected stock returns. Journal of Financial Economics 41, 401-440.

Harvey, C.R., 1988. The real term structure and consumption growth. Journal of Financial Economics 22, 305-334.

Harvey, C.R., 1989. Time-varying conditional covariances in tests of asset pricing models. Journal of Financial Economics 24, 289-318.

Harvey, C.R., 1990. Equity style indexes: Tools for better performance evaluation and plan management. Frank Russell Company white paper.

Harvey, C.R., 1991a. The term structure and world economic growth. Journal of Fixed Income 1, $4-17$.

Harvey, C.R., 1991b. The world price of covariance risk. Journal of Finance 46, 111-157.

Harvey, C.R., 1993. Global risk exposure to a trade-weighted foreign currency index. Working paper, Duke University.

Jegadeesh, N., Titman, S., 1993. Returns of buying winners and selling losers. Journal of Finance 48, 65-91. 
Kester, C.W., Luehrman, T.A., 1989. Real interest rates and the cost of capital. Japan and the World Economy 1, 279-301.

Kim, D., 1995. The errors in the variables problem in the cross-section of expected stock returns. Journal of Finance 50, 1605-1634.

King, M., Sentana, E., Wadhwani, S., 1994. Volatility and links between national markets. Econometrica 62, 901-934.

Kothari, S.P., Shanken, J., Sloan, R.G., 1995. Another look at the cross-section of expected stock returns. Journal of Finance 50, 185-224.

Lakonishok, J., Shliefer, A., Vishny, R.W., 1994. Contrarian investment, extrapolation, and risk. Journal of Finance 49, 1541-1578.

Lintner, J., 1965. The valuation of assets and the selection of risky investments in stock portfolios and capital budgets. Review of Economics and Statistics 47, 13-37.

Mandelker, G., Tandon, K., 1985. Common stock returns, real activity and inflation: Some international evidence. Journal of International Money and Finance 4, 267-286.

Mark, N.C., 1985. On time-varying risk premia in the foreign exchange market: An econometric analysis. Journal of Monetary Economics 16, 3-18.

Merton, R.C., 1973. An Intertemporal capital asset pricing model. Econometrica 41, 867-887.

Morningstar, 1995. The Morningstar, Inc. On Disc data base.

Rosenberg, B., Marathe, V., 1979. Tests of capital asset pricing hypotheses. Research in Finance 1, $115-223$.

Rosenberg, B., Reid, K., Lanstein, R., 1985. Persuasive evidence of market inefficiency. Journal of Portfolio Management, pp. 9-17.

Ross, S.A., 1976. The arbitrage theory of capital asset pricing. Journal of Economic Theory 13, $341-360$.

Ross, S.A., Walsh, M., 1983. A simple approach to the pricing of risky assets with uncertain exchange rates. In: Hawkins, R., Levich, R., Wihlborg, C., (Eds.), The Internationalization of Financial Markets and National Economic Policy. JAI Press, Greenwich, CT.

Sharpe, W.F., 1964. Capital asset prices: A theory of market equilibrium under conditions of risk. Journal of Finance 19, 425-442.

Solnik, B., 1974a. An equilibrium model of the international capital market. Journal of Economic Theory $8,500-524$.

Solnik, B., 1974b. The international pricing of risk: An empirical investigation of the world capital market structure. Journal of Finance 29, 48-54.

Solnik, B., 1977. Testing international asset pricing: Some pessimistic views. Journal of Finance 32, 503-511.

Solnik, B., 1993. The unconditional performance of international asset allocation strategies using conditioning information. Journal of Empirical Finance 1, 33-55.

Stulz, R.M., 1981a. A Model of International Asset Pricing. Journal of Financial Economics 9, 383-406.

Stulz, R.M., 1981b. On the effects of barriers to international investment. Journal of Finance 36, 923-934.

Stulz, R.M., 1984. Pricing capital assets in an international setting: An Introduction. Journal of International Business Studies 15, 55-74.

Stulz, R.M., Wasserfallen, W., 1995. Foreign equity investment restrictions, capital flight, and shareholder wealth maximization: Theory and evidence. Review of Financial Studies 8, 10191105.

Wadhwani, S., Shah, M., 1993. Valuation indicators and stock market prediction: I. Working paper, Goldman Sachs International, Ltd., London.

Wheatley, S., 1988. Some tests of the consumption-based asset pricing model. Journal of Monetary Economics 22, 193-216. 